\title{
Anlotinib Inhibits PFKFB3-Driven Glycolysis in Myofibroblasts to Reverse Pulmonary Fibrosis
}

\author{
Weimou Chen ${ }^{1+}$, Jinming Zhang ${ }^{1 \dagger}$, Wenshan Zhong ${ }^{1 \dagger}$, Yuanyuan Liu ${ }^{1}$, Ye Lu ${ }^{1}$, Zhaojin Zeng ${ }^{1}$, \\ Haohua Huang ${ }^{1}$, Xuan Wan ${ }^{1}$, Xiaojing Meng ${ }^{2}$, Fei Zou ${ }^{2}$, Shaoxi Cai ${ }^{1 *}$ and Hangming Dong ${ }^{1 *}$ \\ ${ }^{1}$ Chronic Airways Diseases Laboratory, Department of Respiratory and Critical Care Medicine, Nanfang Hospital, Southern \\ Medical University, Guangzhou, China, ${ }^{2}$ Guangdong Provincial Key Laboratory of Tropical Disease Research, Department of \\ Occupational Health and Medicine, School of Public Health, Southern Medical University, Guangzhou, China
}

Idiopathic pulmonary fibrosis (IPF) is a fatal disease in which the normal alveolar network is gradually replaced by fibrotic scars. Current evidence suggests that metabolic alterations correlate with myofibroblast activation in IPF. Anlotinib has been proposed to have antifibrotic effects, but the efficacy and mechanisms of anlotinib against lung fibrosis have not been systematically evaluated. The antifibrotic effects of anlotinib were evaluated in bleomycin-induced mouse models and transforming growth factor-beta 1 (TGF- $\beta 1$ )stimulated lung fibroblasts. We measured lactate levels, 2-NBDG glucose uptake and the extracellular acidification rate (ECAR) to assess glycolysis in fibroblasts. RNA-protein coimmunoprecipitation (RIP) and polysome analyses were performed to investigate novel mechanisms of glycolytic reprogramming in pulmonary fibrosis. We found that anlotinib diminished myofibroblast activation and inhibited the augmentation of glycolysis. Moreover, we show that PCBP3 posttranscriptionally increases PFKFB3 expression by promoting its translation during myofibroblast activation, thus promoting glycolysis in myofibroblasts. Regarding mechanism, anlotinib exerts potent antifibrotic effects by downregulating PCBP3, reducing PFKFB3 translation and inhibiting glycolysis in myofibroblasts. Furthermore, we observed that anlotinib had preventative and therapeutic antifibrotic effects on bleomycin-induced pulmonary fibrosis. Therefore, we identify PCBP3 as a protein involved in the regulation of glycolysis reprogramming and lung fibrogenesis and propose it as a therapeutic target for pulmonary fibrosis. Our data suggest that anlotinib has antifibrotic effects on the lungs, and we provide a novel mechanism for this effect. Anlotinib may constitute a novel and potent candidate for the treatment of pulmonary fibrosis.

Keywords: pulmonary fibrosis, anlotinib, glycolysis, PFKFB3, PCBP3
Abbreviations: IPF, idiopathic pulmonary fibrosis; BLM, bleomycin; RBP, RNA binding protein; $\alpha$-SMA, $\alpha$-smooth muscle actin; ECM, extracellular matrix; PFKFB3, 6-phosphofructo-2-kinase/fructose-2, 6-bisphosphatase-3; F2, 6BP, fructose-2, 6bisphosphate; PFK1, phosphofructokinase-1; TKI, tyrosine kinase inhibitor; VEGFR, vascular endothelial growth factor receptor; EGFR, epidermal growth factor receptor; FGFR, fibroblast growth factor receptor; PDGFR, platelet-derived growth factor receptor; TGF- $\beta 1$, transforming growth factor-beta 1 ; TV, tidal volume; Cdyn, dynamic compliance; RI, resistance; HYP, hydroxyproline; IHC, immunohistochemical; H\&E, Hematoxylin and eosin; MLF, mouse lung fibroblasts; PPI, protein-protein interaction; MAPK, mitogen-activated protein kinase; ECAR, extracellular acidification rate; siRNA, small interfering RNA; DMSO, dimethylsulfoxide; PBS, phosphate buffered saline; DMEM, Dulbecco's Modified Eagle Medium; FBS, fetal bovine serum; DAPI, 4',6-diamidino-2-phenylindole. 


\section{INTRODUCTION}

Fibrosis can develop in most organs and cause organ failure. The most common type of lung fibrosis is idiopathic pulmonary fibrosis (IPF), which is highly prevalent and associated with a dramatically increased disease burden worldwide (Wynn and Ramalingam, 2012; Hutchinson et al., 2015). Overall, the development of new therapeutics should be pursued. Currently, only pirfenidone and nintedanib have been approved as therapeutics for IPF (Taniguchi et al., 2010; Sato et al., 2017), and as both drugs have limited efficacy (Spagnolo and Maher, 2017), there is an urgent need to identify new potential therapeutic agents for IPF patients.

Upon chronic microinjury to the alveolar epithelium, fibroblast activation and transdifferentiation into myofibroblasts are among the first responses detectable at the site of damage (Plantier et al., 2018). Myofibroblasts are characterized by de novo expression of $\alpha$-smooth muscle actin ( $\alpha$-SMA), the formation of stress fibers, and enhanced abilities to proliferate, migrate, and produce extracellular matrix (ECM) (Hinz, 2012; Hinz et al., 2012; Liu et al., 2021). These cells drive a wound-healing response that relies on the deposition of collagen-rich ECM and activates transforming growth factor-beta 1 (TGF- $\beta 1$ ) signaling (Kenyon et al., 2003; Sapudom et al., 2015; Nigdelioglu et al., 2016). This transient response must be tightly controlled, otherwise it can become persistent and lead to excessive matrix accumulation and fibrosis. Understanding the molecular bases of fibroblast activation is therefore essential in identifying novel and efficient antifibrotic therapeutic targets to reduce the incidence, morbidity and mortality of people suffering from clinically refractory disorders, including IPF.

Metabolic perturbation is implicated in the pathogenesis of several kinds of tissue fibrosis (DeBerardinis and Thompson, 2012; Chen et al., 2018), including pulmonary fibrosis (Para et al., 2019; Bueno et al., 2020). To cope with the high energy demands of myofibroblasts, including increases in proliferation and matrix production, it is reasonable that activated myofibroblasts exhibit augmented aerobic glycolysis to meet additional bioenergetic and biosynthetic demands, even in oxygen-rich conditions, similar to observations in many cancer cells and other nonmalignant proliferating cells. A major driver of glycolysis is 6phosphofructo-2-kinase/fructose-2,6-bisphosphatase-3 (PFKFB3), which produces fructose-2,6-bisphosphate (F2,6BP), the most potent allosteric activator of the glycolytic rate-limiting enzyme phosphofructokinase-1 (PFK1) (Van Schaftingen et al., 1982; Cao et al., 2019). Previous studies have shown that augmentation of aerobic glycolysis is an essential step during myofibroblast activation (Para et al., 2019). Ramping down glycolysis is effective in diminishing myofibroblast activation, thus limiting lung fibrosis. However, metabolism-based therapeutics for treating fibrotic disorders are still lacking.

Anlotinib (AL3818) hydrochloride is a novel multitargeted tyrosine kinase inhibitor (TKI) that targets the receptor tyrosine kinases vascular endothelial growth factor receptor (VEGFR) 1 thru 3, epidermal growth factor receptor (EGFR), fibroblast growth factor receptor (FGFR) 1 thru 4, platelet-derived growth factor receptor (PDGFR) $\alpha$ and $\beta$, and stem cell factor receptor (Sun et al., 2016; Xie et al., 2018). Many studies have reported the therapeutic effects of anlotinib in several diseases, such as nonsmall cell lung cancer (Liang et al., 2019), endometrial cancers (Taurin et al., 2018) and osteosarcoma (Liang et al., 2019). Interestingly, the targets of anlotinib are similar to those of nintedanib, a drug that has been approved for the treatment of IPF. A recent report suggested that intraperitoneal administration of anlotinib attenuates bleomycininduced lung fibrosis in mice by suppressing the TGF- $\beta$ signaling pathway (Ruan et al., 2020). Nevertheless, the mechanism by which anlotinib resolves lung fibrosis and whether anlotinib may be therapeutically used to improve lung function are not well understood.

In the current study, we analyzed the antifibrotic effect of anlotinib on TGF- $\beta 1$-induced fibroblast transdifferentiation and bleomycin-induced pulmonary fibrosis. Our data suggest that anlotinib therapy decreases fibrotic markers in vitro and in vivo. The antifibrotic effect of anlotinib is associated with inhibition of PFKFB3-dependent glycolysis, which is posttranscriptionally regulated by the RNA binding protein PCBP3. These findings provide a theoretical basis for the clinical development and application of anlotinib for the treatment of pulmonary fibrosis.

\section{MATERIALS AND METHODS Isolation of Primary Mouse Fibroblast Cultures}

Normal mouse primary fibroblasts were generated by culturing the lungs of C57BL/6 as previously described (Meng et al., 2014). The cells were cultured in Dulbecco's modified Eagle's medium (DMEM, Gibco, United States) supplemented with 15\% fetal bovine serum (FBS, PAN, German). The cells were cultured at $37^{\circ} \mathrm{C}$ in $5 \% \mathrm{CO} 2$ and $95 \%$ humidity. Unless specifically noted, all experiments were performed with cells at passage 3 .

\section{Cell Lines}

Human lung fibroblast line IMR90 was purchased from American Type Culture Collection (Manassas, VA). IMR90 were maintained in DMEM supplemented with $10 \%$ FBS, 100 units/mL penicillin, and $100 \mathrm{~g} / \mathrm{ml}$ streptomycin in $5 \% \mathrm{CO} 2$ and $95 \%$ humidity at $37^{\circ} \mathrm{C}$.

\section{Western Blotting}

Cells or dissected mouse lung tissue samples were lysed in ice-cold RIPA lysis buffer with protease inhibitors. Protein concentrations were determined using a BCA Protein Quantitative Analysis Kit (Fudebio-tech) after which protein samples were separated by $8-12 \%$ SDS-PAGE and transferred onto polyvinylidene difluoride membranes (Millipore). The membranes were then incubated at room temperature for $1 \mathrm{~h}$ in TBST containing 5\% BSA. After blocking, the membranes were incubated with primary antibodies for $24 \mathrm{~h}$ at $4^{\circ} \mathrm{C}$.The following primary antibodies were used: antiFibronectin (Abcam, ab268020); anti-Collagen I (affinity, AF7001); anti-alpha smooth muscle (Abcam, ab5694); anti-PFKFB3 (Abcam, ab181861); anti-Beta actin (proteintech, 66009-1-Ig); antiHexokinase 2 (proteintech, 22029-1-AP); anti-PKM2 (Proteintech, 15822-1-AP); anti-LDHA (Proteintech, 19987-1-AP); anti-LDHB (Proteintech, 14824-1-AP); and anti-PCBP3 (Abcam, ab154252). Then, the membranes were washed three times with TBST and incubated with donkey anti-rabbit IgG H\&L (Abcam, ab175772) for 
$1 \mathrm{~h}$ at room temperature. The membranes were developed using the ECL method according to the manufacturer's instructions (Millipore) and detected on a GeneGnome XRQ chemiluminescence imaging system (Syngene). ImageJ was used to calculate the relative density of proteins.

\section{Immunofluorescence Staining}

The culture medium was washed away with PBS. The cultured cells were fixed with $4 \%$ paraformaldehyde for $30 \mathrm{~min}$. Then, the samples were permeabilized with $0.5 \%$ Triton X-100 in PBS for 10 min, blocked with $1 \%$ BSA in PBS for $1 \mathrm{~h}$ at room temperature, and incubated with primary antibodies at $4^{\circ} \mathrm{C}$ overnight. The primary antibodies included anti- Fibronectin (Abcam, ab268020), anti-alpha smooth muscle (Abcam, ab5694) and anti-PCBP3 (Abcam, ab154252). Then, the cells were washed three times with PBS and incubated with goat anti-rabbit IgG/ Alexa Fluor 555-conjugated secondary antibodies (Biosynthesis, bs-0296GA488 and bs-0295G-AF555) for $1 \mathrm{~h}$ at room temperature followed by $10 \mathrm{~min}$ of DAPI (4',6-diamidino-2phenylindole dihydrochloride) staining to visualize cell nuclei visualization as previously described (Chen et al., 2021).

\section{Quantitative RT-PCR (qPCR)}

Total RNA was isolated from primary mouse lung fibroblasts using RNA MiniPrep Kits (Zymo Research, R2050). Reverse transcription reactions were performed with a PrimeScriptTM II 1st strand cDNA synthesis Kit (Takara, 6210A/B) according to the manufacturer's recommendations. qPCR analysis was performed using a HiScript RT- SuperMix for qPCR kit (Vazyme, R223-01) with a CFX96 Touch Real-Time PCR Detection System. The mRNA levels of target genes were normalized to the $\beta$-actin mRNA level. Primers used for qPCR are listed in (Table 1).

\section{Wound-Healing Migration Assay}

Cells were seeded in six-well plates and grown until they reach $100 \%$ confluence. A "wound" was subsequently created with a sterile $100 \mu \mathrm{L}$ pipette tip. The cells were pretreated with anlotinib $(1 \mu \mathrm{M})$ for $3 \mathrm{~h}$ and then exposed to TGF- $\beta 1(10 \mathrm{ng} / \mathrm{ml})$ for an additional $24 \mathrm{~h}$. After $24 \mathrm{~h}$, the cells were fixed with $4 \%$ paraformaldehyde, and images were obtained using a fluorescence microscope. Wound area can be calculated by manually tracing the cell-free area in captured images using the ImageJ public domain software (NIH, Bethesda, MD).

\section{Cell Proliferation Assay}

Cell proliferation was determined by the CCK-8 Kit (Dojindo Laboratories) according to the manufacturer's instructions. Briefly, $10 \mu \mathrm{L}$ of CCK- 8 solution was added to cultured cells in each well, followed by incubation at $37^{\circ} \mathrm{C}$ for $1 \mathrm{~h}$. The $\mathrm{OD}$ values were measured at $450 \mathrm{~nm}$ using a microplate reader. EdU staining was conducted using the BeyoClick ${ }^{\mathrm{TM}}$ EdU Cell Proliferation Kit with Alexa Fluor 594 (Beyotime, Cat. No: C00788L). Cells were washed with PBS. Fresh DMEM was added, and then, $10 \mu \mathrm{M}$ EdU was added into the medium. The cells were incubated for $2 \mathrm{~h}$ at $37^{\circ} \mathrm{C} / 5 \% \mathrm{CO} 2$. After the incubation, the cells were washed with PBS to remove the DMEM and the free EdU probe. The cells were then fixed in $4 \%$ paraformaldehyde at room temperature for
30 min before being stained with DAPI for 3 min. After an additional wash in PBS, the cells were observed under Nikon ECLIPSE TS100 (Japan).

\section{Glucose Uptake Assay}

Primary mouse lung fibroblasts were pretreated with anlotinib $(1 \mu \mathrm{M})$ for $3 \mathrm{~h}$ and then exposed to TGF- $\beta 1(10 \mathrm{ng} / \mathrm{ml})$ for an additional $24 \mathrm{~h}$. Then, the four types of cells were detached and transferred to a 96-well plate in fresh growth medium at a density of 10,000 cells per well for the direct 2-NBDG glucose uptake assay. The cells were rinsed twice with PBS. Glucose uptake was initiated by the addition of $100 \mu \mathrm{M} 2-\mathrm{NBDG}$ to each well. After $30 \mathrm{~min}$, the medium was removed. The plates were then rinsed with PBS, and the fluorescence was measured at an excitation wavelength of $485 \mathrm{~nm}$ and an emission wavelength of $535 \mathrm{~nm}$.

\section{Intracellular and Extracellular Lactate Analysis}

To measure lactate production, cells were treated as described for the glucose uptake assay. One hundred thousand cells were then plated into a 12-well plate and incubated in DMEM containing 10\% FBS for $10 \mathrm{~h}$. To measure the secretion of lactate, the media were removed, and the cells were incubated in FBS-free DMEM. After incubation for $1 \mathrm{~h}$, the supernatant was collected to measure lactate production (Biovision). The reaction mixture was incubated for $30 \mathrm{~min}$ at room temperature in the dark. The lactate levels were measured at $450 \mathrm{~nm}$ in a microplate reader and normalized to the protein concentrations. To measure the lactate levels in mouse lung tissue, $10 \mathrm{mg}$ of lung tissues was isolated and homogenized in assay buffer (Biovision). The samples were centrifuged, and the soluble fractions were measured and normalized to the protein concentrations.

\section{Extracellular Acidification Rate}

The extracellular acidification rate (ECAR) was measured using the Agilent Seahorse XFp Extracellular Flux Analyzer (Seahorse Bioscience). Experiments were performed according to the manufacturer's instructions. ECAR were measured using Seahorse XF Glycolysis Stress Test Kit (Agilent Technologies). Briefly, cells were transfected or infected as in glucose uptake assay. The transfected cells were harvested and the cell number was counted. After baseline measurements, glucose, the oxidative phosphorylation inhibitor oligomycin, and the glycolytic inhibitor 2-DG were sequentially injected into each well at the indicated time points. Data were analysed by Seahorse XFp Wave software. ECAR is reported in $\mathrm{mpH} /$ minute. The cells in each well were digested by trypsin digestion (Gibco, United States), and count cell numbers by cell counting chamber. The results were normalized to normalized to cell number in each well.

\section{RNA Immunoprecipitation (RIP)}

Cells were rinsed twice with ice-cold PBS and lysed with an equal pellet volume of RIPA-2 buffer. Protein-A Dynabeads (Invitrogen) were incubated with either mouse IgG or FLAG antibody (Abcam, ab205606). Beads coated in antibody were resuspended in NT2 buffer. Thawed and clarified lysates were added and the bead/antibody/lysate mixture was incubated at 
$4^{\circ} \mathrm{C}$ overnight rotating end-over-end. Beads were washed with cold NT2 buffer five times. Proteinase K treatment released RNAs from bound proteins and input and bound RNA was isolated with TRIzol (Invitrogen) and reverse transcribed as described above.

\section{Polysome Analysis}

Cells were transfected with empty vector or Flag-PCBP3 and incubated with $100 \mathrm{~g} / \mathrm{ml}$ cycloheximide for $10 \mathrm{~min}$ and lysed with polysome extraction buffer containing $20 \mathrm{mM}$ Tris- $\mathrm{HCl}, \mathrm{pH} 7.5$, $100 \mathrm{mM} \mathrm{KCl}, 5 \mathrm{mM} \mathrm{MgCl} 2$ and $0.5 \% \mathrm{NP}-40$ as previously described (Kim et al., 2015). Cytoplasmic lysates were fractionated by ultracentrifugation through $10-50 \%$ linear sucrose gradients and divided into 12 fractions. The total RNA in each fraction was extracted and analyzed by quantitative RT-PCR analysis.

\section{Overexpression Experiments and RNA Interference}

The Plasmid vector encoding PCBP3 and the empty vector were purchased from Hanbio (Shanghai, China). Primary mouse lung fibroblasts were cultured in six well plates (105 cells/well) and added with $2.5 \mu \mathrm{g}$ of target plasmid per well. After $12 \mathrm{~h}$, the transfection medium was changed to normal medium. Effects of overexpression on mRNA and protein levels were examined $36 \mathrm{~h}$ later. The siRNA targeting mouse PFKFB3 (PFKFB3 siRNA: $5^{\prime}$ CCUCUUGACCCUGAUAAAUTT- $3^{\prime}$ ) were synthesized by Genepharma Co. (Shanghai, China). Primary mouse lung fibroblasts were cultured in six well plates (105 cells/well) and transfected using Lipofectamine 3,000 (Invitrogen, CA) with PFKFB3 siRNA or negative control siRNA (NC siRNA) for $48 \mathrm{~h}$ following the manufacturer's instructions.

\section{Animal Experiments}

All experiments were conducted in accordance with protocols approved by the Southern Medical University Institutional Animal Care and Use Committee. Female mice (C57BL/6), 6-8 weeks of age, were purchased from Southern Medical University. The mice were kept on a $12 \mathrm{~h}$ light-dark cycle with free access to food and water. For bleomycin administration, the mice were anesthetized with 2, 2, 2tribromoethanol (Sigma-Aldrich), followed by intratracheal instillation of BLM (5 U/kg, i. t.) in $50 \mu \mathrm{L}$ phosphate-buffered saline (PBS) or equally volume PBS for 21 days. The mice were administered dimethyl sulfoxide (DMSO) (control group) or anlotinib ( $1 \mathrm{mg} / \mathrm{kg}$, i. p.) once daily for 21 consecutive days. Further experiments were designed to measure the effects of delayed anlotinib administration. Anlotinib treatment was initiated 1 week after exposure to bleomycin, and the mice were administered with anlotinib ( 1 or $2 \mathrm{mg} / \mathrm{kg} /$ day) for 2 weeks, and the mice were sacrificed at day 21 . The lungs were harvested for further analyses.

\section{Pulmonary Function Test}

At endpoint, at least 5 mice from each group were anesthetized with 2,2,2-tribromoethanol in saline, tracheotomized below the larynx, and intubated with a tracheal cannula. After the surgery, the mice were placed inside the plethysmographic chamber and the cannula was connected to the machine. Pulmonary function was measured by pulmonary function test system (BUXCO, United States). The system's software automatically records and displays the pulmonary function parameters.

\section{Hydroxyproline Assay}

Lung collagen content was measured with a hydroxyproline (HYP) kit (Nanjing Jian Cheng Institute, Nanjing, China). The lung tissues were prepared for hydrolysis, adjusting the $\mathrm{PH}$ value to 6.0-6.8. Subsequently, the developing solution was added to the tissues that were incubated at $37^{\circ} \mathrm{C}$ for $5 \mathrm{~min}$. Absorbance was read at $550 \mathrm{~nm}$ using a microplate reader. Data were expressed as micrograms $(\mu \mathrm{g})$ of HYP per mg of wet lung tissue.

\section{Materials}

TGF- $\beta 1$ were purchased from R\&D Systems, Inc. (Minneapolis, MN, United States). Anlotinib dihydrochloride (AL3818, S8726) were purchased from Selleck (Houston, TX, United States).

\section{Statistical Analysis}

The results are expressed as the means \pm standard deviation (SD). Multigroup comparisons were performed using one-way ANOVA. Student's t-test was used for comparisons between two groups. A $p$ value of less than 0.05 was considered significant. Replicates consisted of at least three independent experiments. Analyses were performed on SPSS version 25.0 (IBM) for Windows and GraphPad Prism version 6.0 (GraphPad Software, CA).

\section{RESULTS}

\section{Anlotinib Represses Myofibroblast Activation and the Profibrogenic Phenotype in vitro}

Given that TGF- $\beta 1$ is the predominant cytokine that stimulates the differentiation of lung fibroblasts into myofibroblasts and induces ECM production (Sapudom et al., 2015; Huang et al., 2020), we examined the effect of anlotinib (the chemical structure is shown in Supplementary Figure S1) on TGF- $\beta 1$-induced activation of primary mouse lung fibroblasts (MLFs). The CCK-8 assay results showed that anlotinib did not cause significant cytotoxicity at doses of $1 \mu \mathrm{M}$ (Figure 1A). To mimic the inhibitory effect of anlotinib on the progression of lung fibrosis, primary MLFs were pretreated with anlotinib $(1 \mu \mathrm{M})$ for $3 \mathrm{~h}$ and then exposed to TGF- $\beta 1(10 \mathrm{ng} / \mathrm{ml})$ for an additional $24 \mathrm{~h}$. Our results demonstrated that TGF- $\beta 1$ induced the expression of fibronectin, collagen I, and $\alpha$-SMA, but anlotinib reversed the expression of these fibrotic markers (Figures 1B,C). Immunofluorescence analysis of $a-S M A$ and fibronectin showed similar results (Figures 1D,E). We also examined whether anlotinib affected the proliferation and migration of fibroblasts, which have been shown to significantly contribute to many fibrotic pathologies (Jarman et al., 2014; Huang et al., 2020). As shown by the EdU (Figures 1F,G) and CCK-8 results (Figure 1H), anlotinib treatment prevented the TGF- $\beta 1$-induced proliferation of 

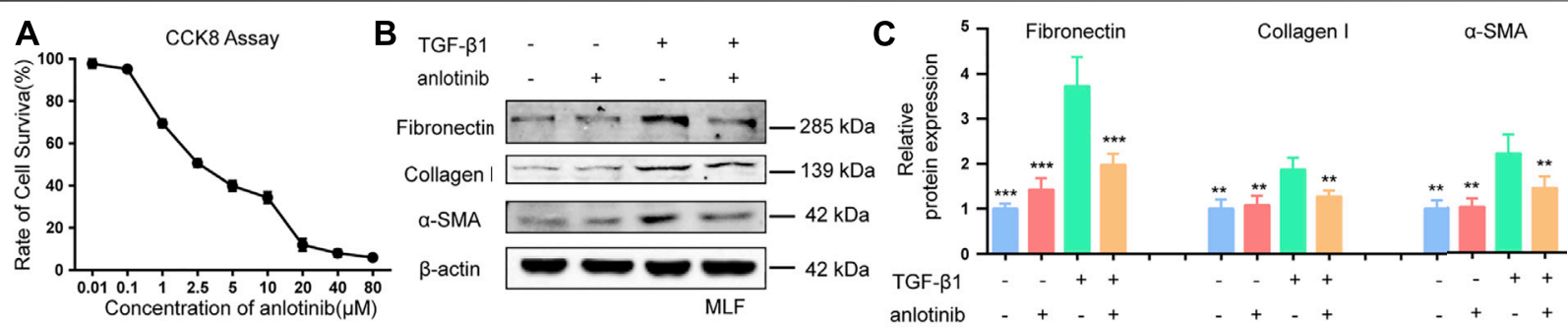

D

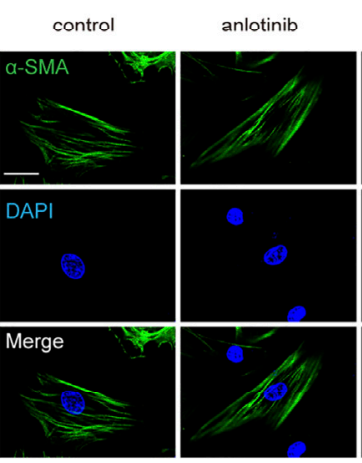

TGF- $\beta 1$

E

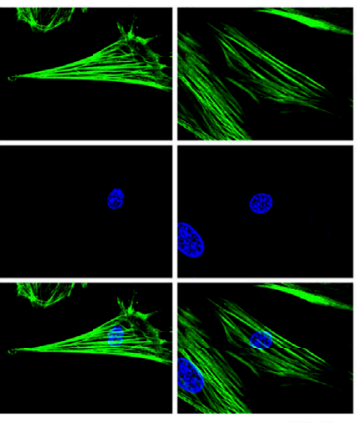

MLF

F
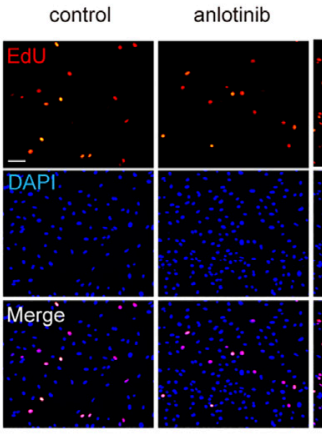

TGF- $\beta$

TGF- $\beta 1+$ anlotinib

G

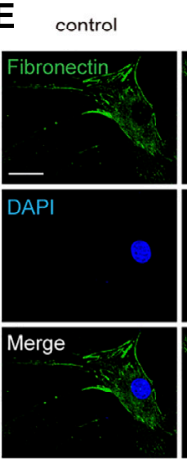

anlotinib

TGF- $\beta 1$

TGF- $\beta 1+$ anlotinib
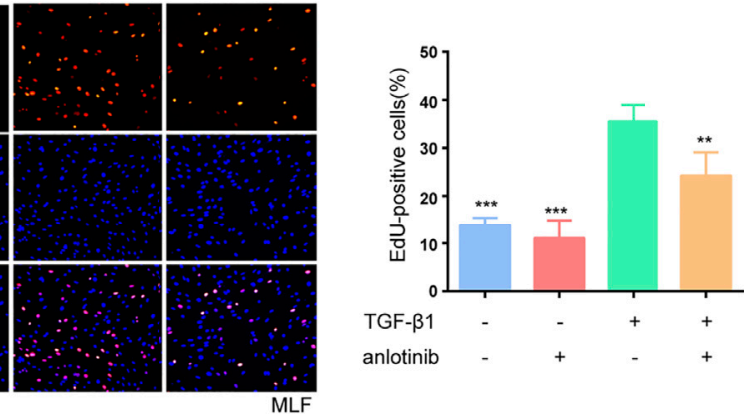

H
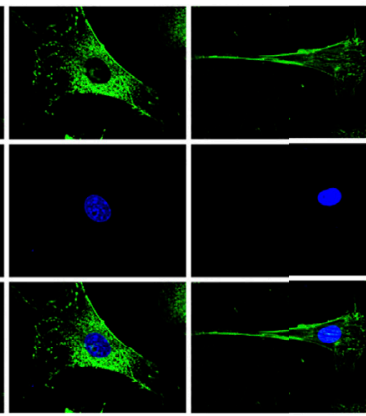

MLF

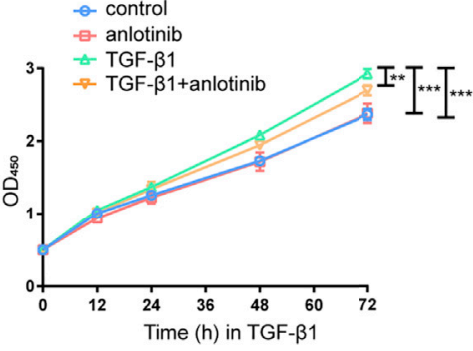

I

control

anlotinib

TGF- $\beta 1$

TGF- $\beta 1+$ anlotinib
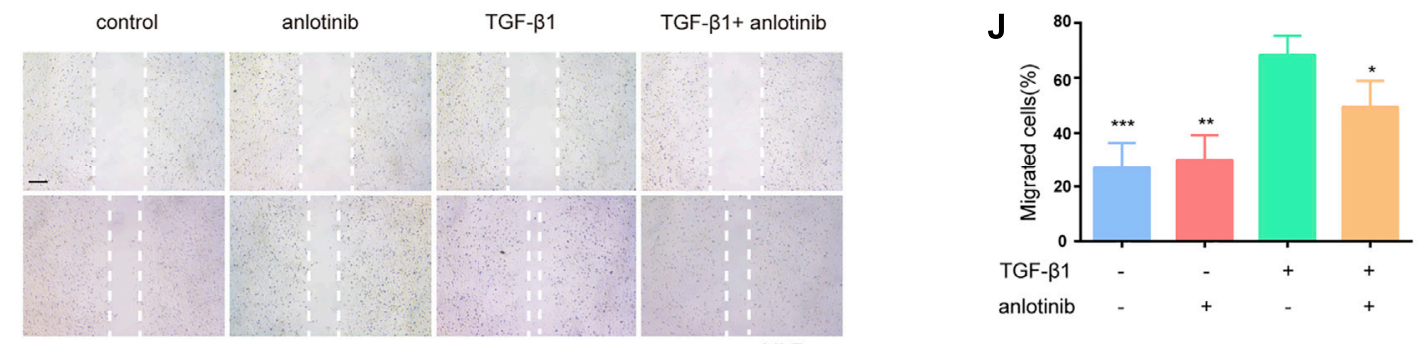

K
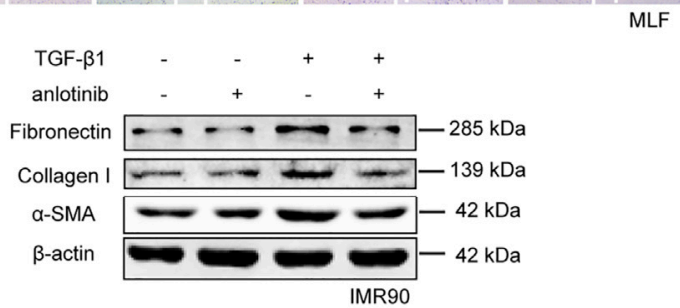

MLF L

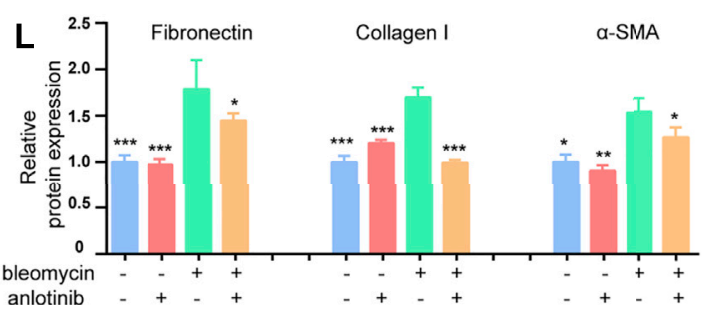

FIGURE 1 | Anlotinib represses myofibroblast activation and the profibrogenic phenotype in vitro.(A) Dose-dependent cytotoxicity of anlotinib in primary mouse lung fibroblast isolated from healthy mice by CCK-8. (B) Western blots analysis of Fibronectin, Collagen I, $\alpha$-SMA and $\beta$-actin in mouse lung fibroblasts treated with anlotinib $(1 \mu \mathrm{M})$ for $3 \mathrm{~h}$ and then exposed to TGF- $\beta 1$ (10 ng/ml) for $3 \mathrm{~h}$, followed by TGF- $\beta 1$ for an additional $24 \mathrm{~h}$. (C) Quantification for the indicated protein (mean \pm SD, $\mathrm{n}=3$ ). Immunofluorescence for $\alpha$-SMA (green) (D) and Fibronectin (green) (E). DAPI-stained nuclei (blue). Scale bar, $25 \mu \mathrm{m}$. (F) An EdU assay was used to observe the proliferative cells. Scale bar, $100 \mu \mathrm{m}$. (G) The number of EdU-positive cells was recorded (mean $\pm \mathrm{SD}, \mathrm{n}=3$ ). (H) A cck8 assay was used to observe the proliferative cells. (I) Representative images to show scratch-wound assay. Scale bars, $100 \mu \mathrm{m}$. Experiments were performed as in B. Images were taken 0 , and $24 \mathrm{~h}$ after assay (white lines indicate wound edge). ( $\mathbf{J})$ Quantitative analysis of migration distance (mean $\pm \mathrm{SD}, \mathrm{n}=3$ ). (K) Western blots analysis of Fibronectin, Collagen I, $\boldsymbol{\alpha}$-SMA and $\beta$-actin in IMR90 cells treated with anlotinib $(1 \mu \mathrm{M})$ for $3 \mathrm{~h}$ and then exposed to TGF- $\beta 1$ (10 $\mathrm{ng} / \mathrm{ml})$ for an additional $24 \mathrm{~h}$. (L) Quantification for the indicated proteins in IMR90 cells (mean $\pm \mathrm{SD}, \mathrm{n}=3$ ). ${ }^{\star} p<0.05,{ }^{* *} p<0.01,{ }^{\star * *} p<0.001$ VS TGF- $\beta 1$-treated group (ANOVA). 
A

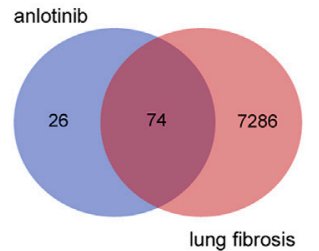

B

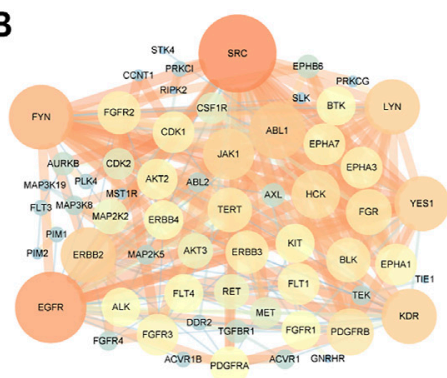

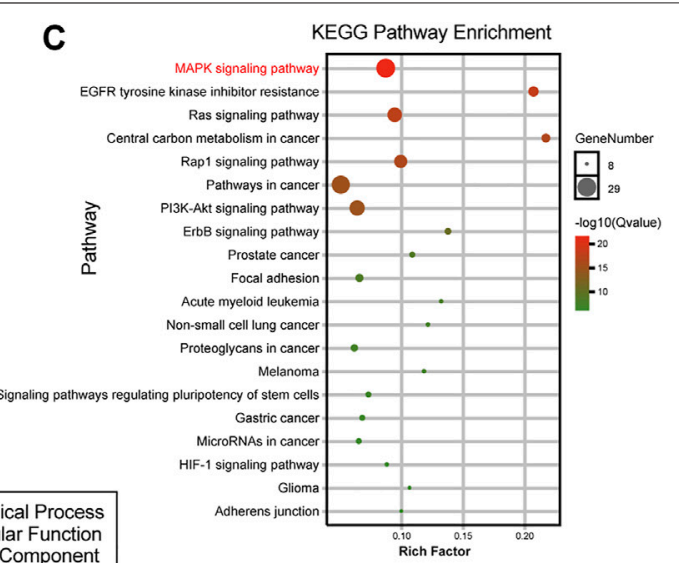

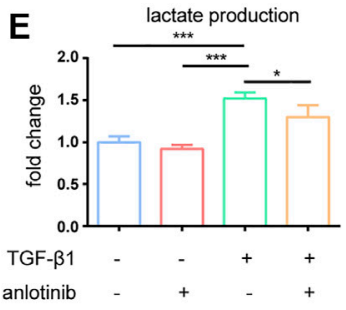

Gliom

0.10
Rich Factor
0.15

D

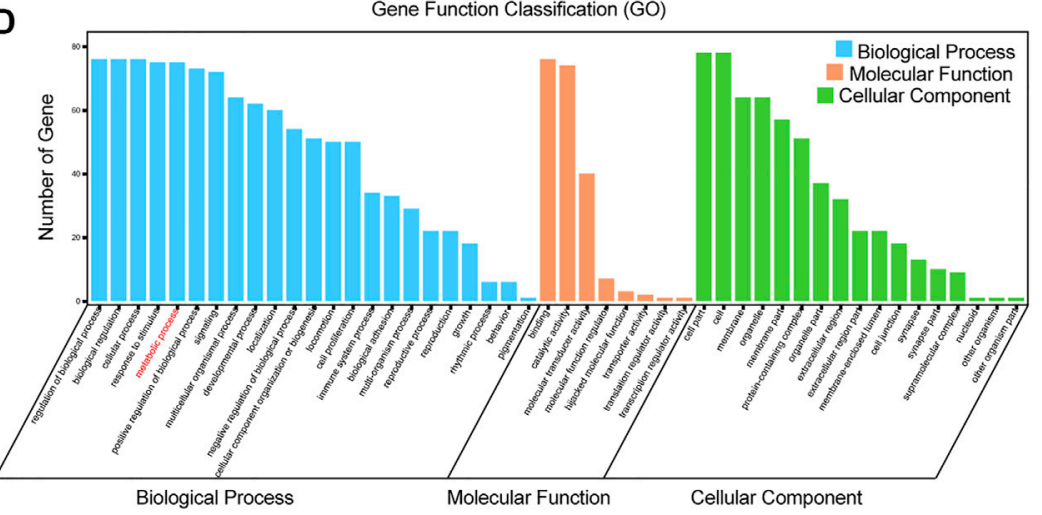

-control

F
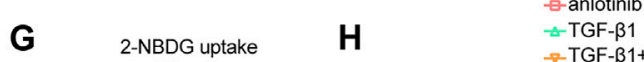

$\triangle$ TGF- $\beta 1$
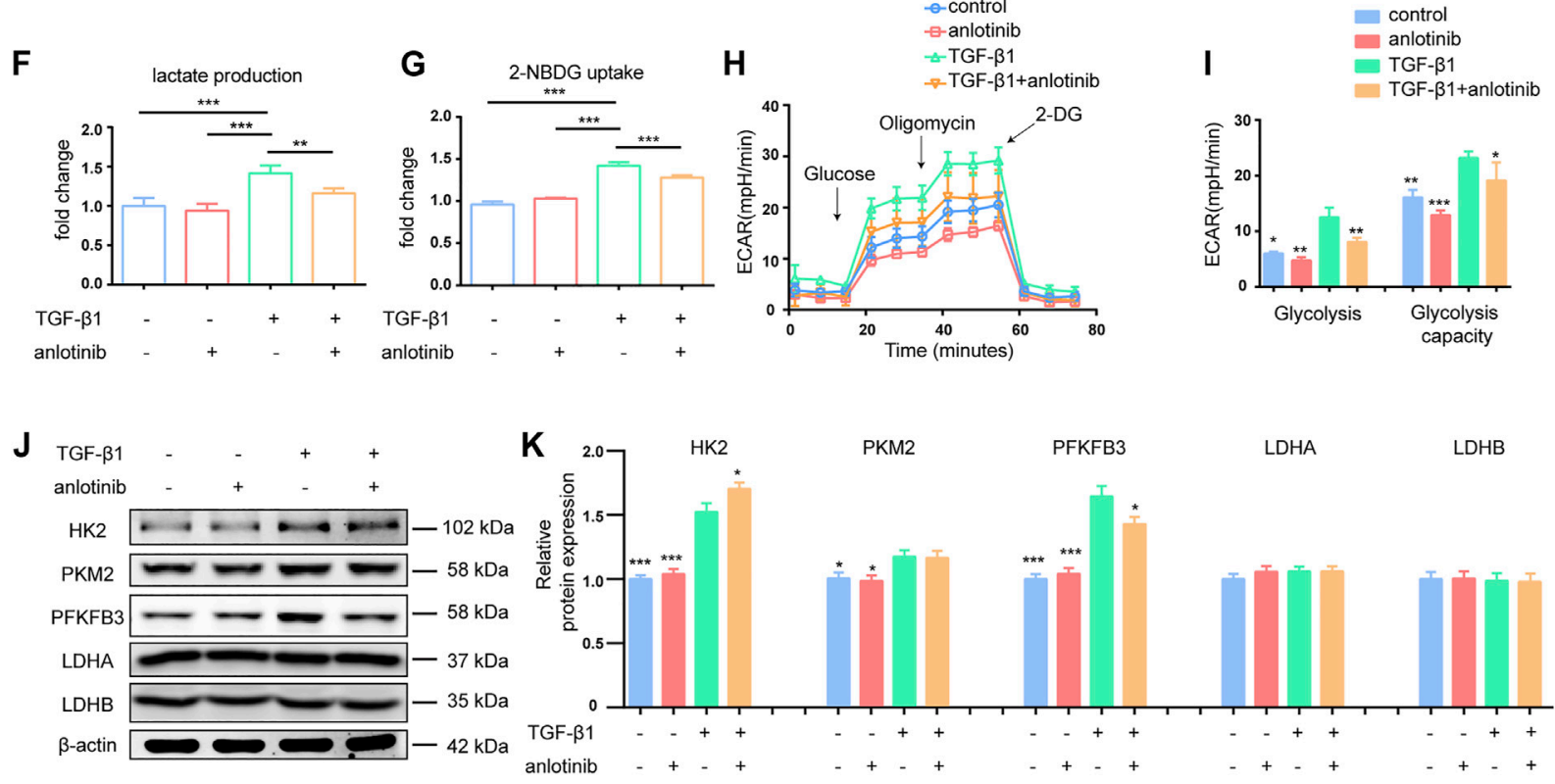

PKM2

PFKFB3

LDHA

LDHB

FIGURE 2 | Anlotinib inhibits PFKFB3-driven glycolysis in lung myofibroblasts. (A) Venn diagram to show the overlaps between anlotinib targets and lung fibrosisrelated targets. (B) Protein-protein interaction (PPI) network of common targets between anlotinib and IPF. (C) The KEGG enrichment analysis of 74 targets of common targets. (D)The GO enrichment for each section listed. The mouse lung fibroblasts were pretreated with anlotinib ( $1 \mu \mathrm{M})$ for $3 \mathrm{~h}$ and then exposed to TGF- $\beta 1$ ( $10 \mathrm{ng} / \mathrm{ml})$ for an additional $24 \mathrm{~h}$, and then the cells were lysed and lactate contents in the cellular lysates (E) and culture media (F) were determined. The data are presented as fold change relative to the levels of the untreated control group (mean $\pm S D, n=3$ ). (G) Glucose uptake detected with 2-NBDG were determined. The data are presented as fold change relative to the levels of the untreated control group (mean $\pm S D, n=3$ ). (H) Extracellular acidification rate (ECAR) was assessed. (I) Glycolysis and glycolysis capacity were quantified and shown as histograms (mean $\pm \mathrm{SD}, \mathrm{n}=3$ ). (J) Western blot analysis of HK2、PKM2、PFKFB3、LDHA and LDHB, $\beta$-actin was used as a loading control. (K) Quantification of HK2、PKM2、PFKFB3、LDHA and LDHB protein levels relative to $\beta$-Actin is shown (mean \pm SD, $\mathrm{n}=3$ ). I, K, ${ }^{\star} p<0.05,{ }^{* \star} p<0.01$, ${ }^{\star \star \star} p<0.001$ VS TGF- $\beta 1$-treated group by ANOVA. 


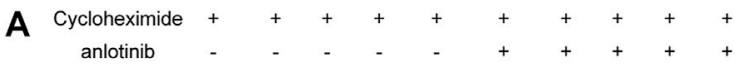
$\begin{array}{lllllllllll}\text { TGF- } \beta 1 & - & - & - & - & - & - & - & - & - & -\end{array}$

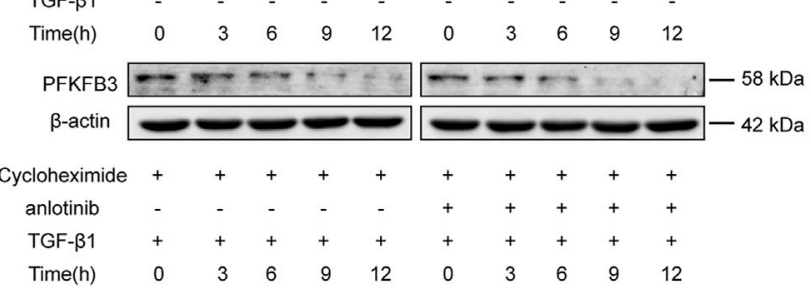

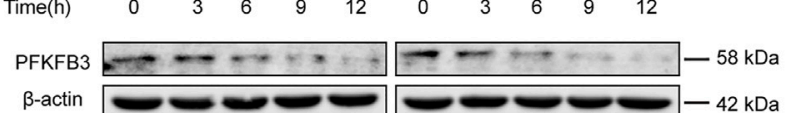

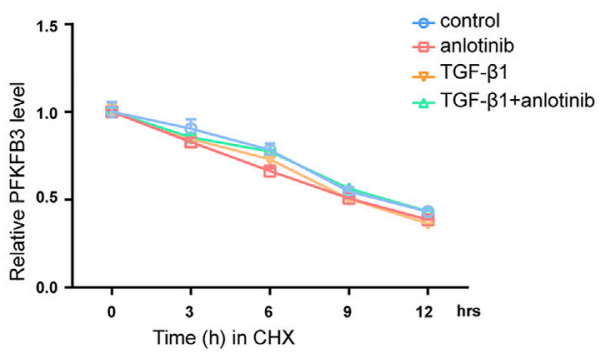

B

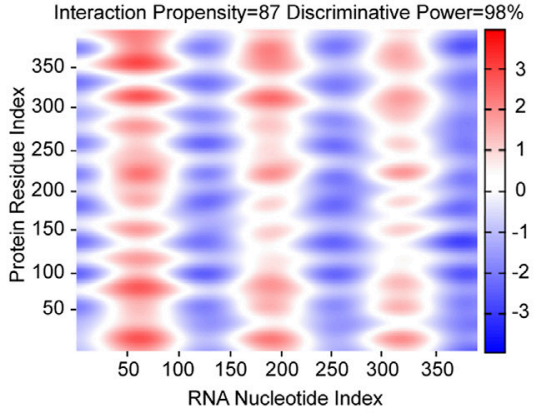

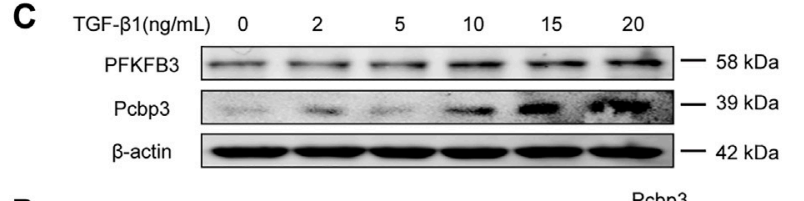

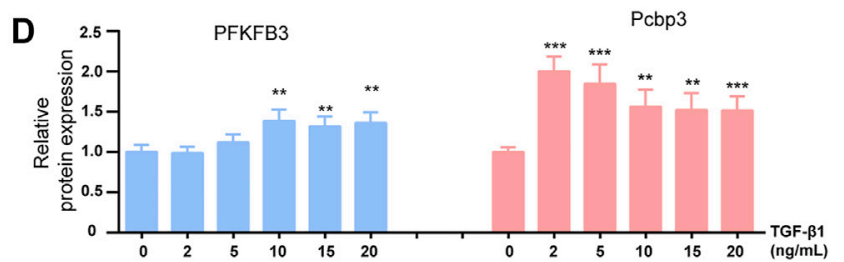

E

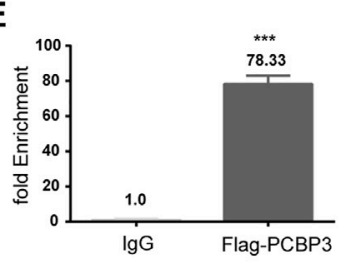

$\mathbf{F}$

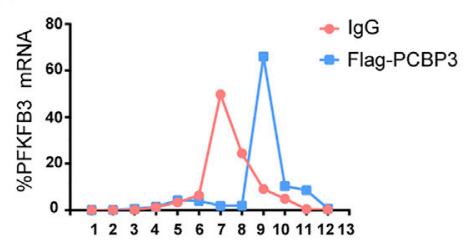

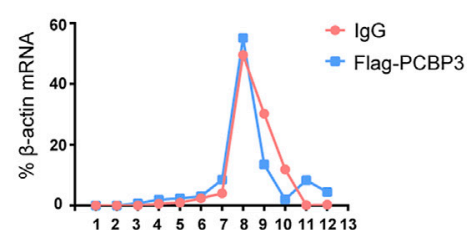

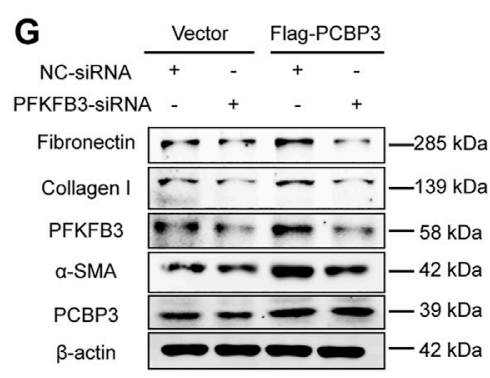

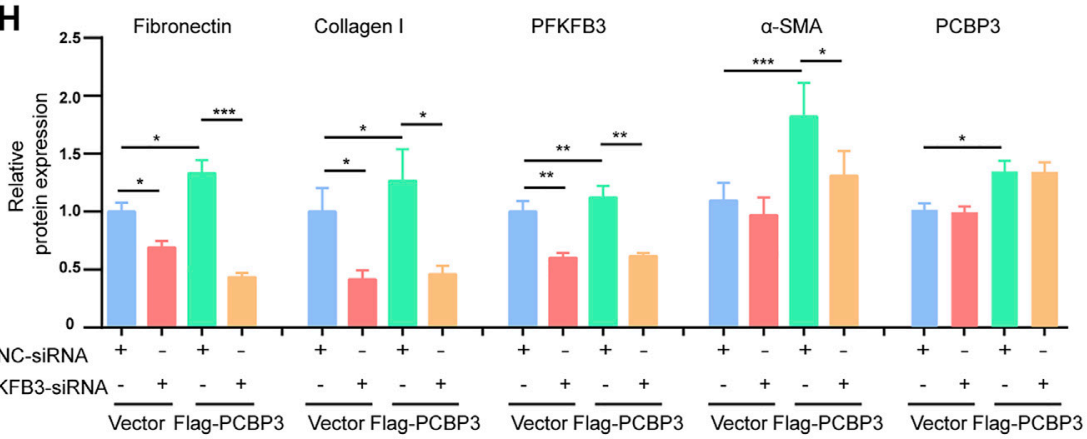

FIGURE 3 | PCBP3 posttranscriptionally increases PFKFB3 expression by promoting its translation during myofibroblast activation.

FIGURE 3 | PCBP3 posttranscriptionally increases PFKFB3 expression by promoting its translation during myofibroblast activation. (A) PFKFB3 degradation in mouse lung fibroblasts when protein synthesis was inhibited by $50 \mu \mathrm{M}$ cycloheximide (mean $\pm S D, n=3$ ). (B) Prediction of RNA-protein interaction of PFKFB3 mRNA with PCBP3 protein using the catRAPID algorithm. Red represents interaction strength. (C) Western blot analysis of PFKFB3 and PCBP3 protein levels in mouse lung fibroblasts stimulated with TGF- $\beta 1$ for the indicated concentrations. (D) Quantification of PFKFB3 and PCBP3 protein levels relative to $\beta$-actin is shown (mean \pm SD, $\mathrm{n}=3,{ }^{\star \star} p<0.01,{ }^{* \star *} p<0.001$ compared with 0 by one-way ANOVA). (E) Quantitative RT-PCR (qPCR) to show the effect of PCBP3 overexpressing on PFKFB3 RNA immunoprecipitation (RIP) in mouse lung fibroblasts. Values were plotted as mean \pm SD from three independent experiments. $p$ value was calculated by Student $t$ test. ${ }^{\star \star \star} p<0.001$. (F) Mouse lung fibroblasts expressing Flag-PCBP3 were fractionated into cytoplasmic extracts through sucrose gradients. The arrow indicates the direction of sedimentation. The distribution of PFKFB3 and $\beta$-actin mRNAs was quantified by RT-PCR analysis of RNA isolated from 12 gradient fractions. Statistical analyses were performed using Student $t$ test. ${ }^{\star \star *} p<0.001$. (G) Mouse lung fibroblasts were transfected with Flag-PCBP3, and then transfected with PFKFB3-siRNAs or NC-siRNA. The levels of Fibronectin、Collagen I、PFKFB3、 $\alpha$-SMA、PCBP3 and $\beta$-actin assessed by western blot. (H) Graphical representation of the relative levels of indicated proteins (mean $\pm \mathrm{SD}, \mathrm{n}=3,{ }^{*} p<0.05,{ }^{* *} p<0.01,{ }^{\star \star *} p<0.001$ by ANOVA). 

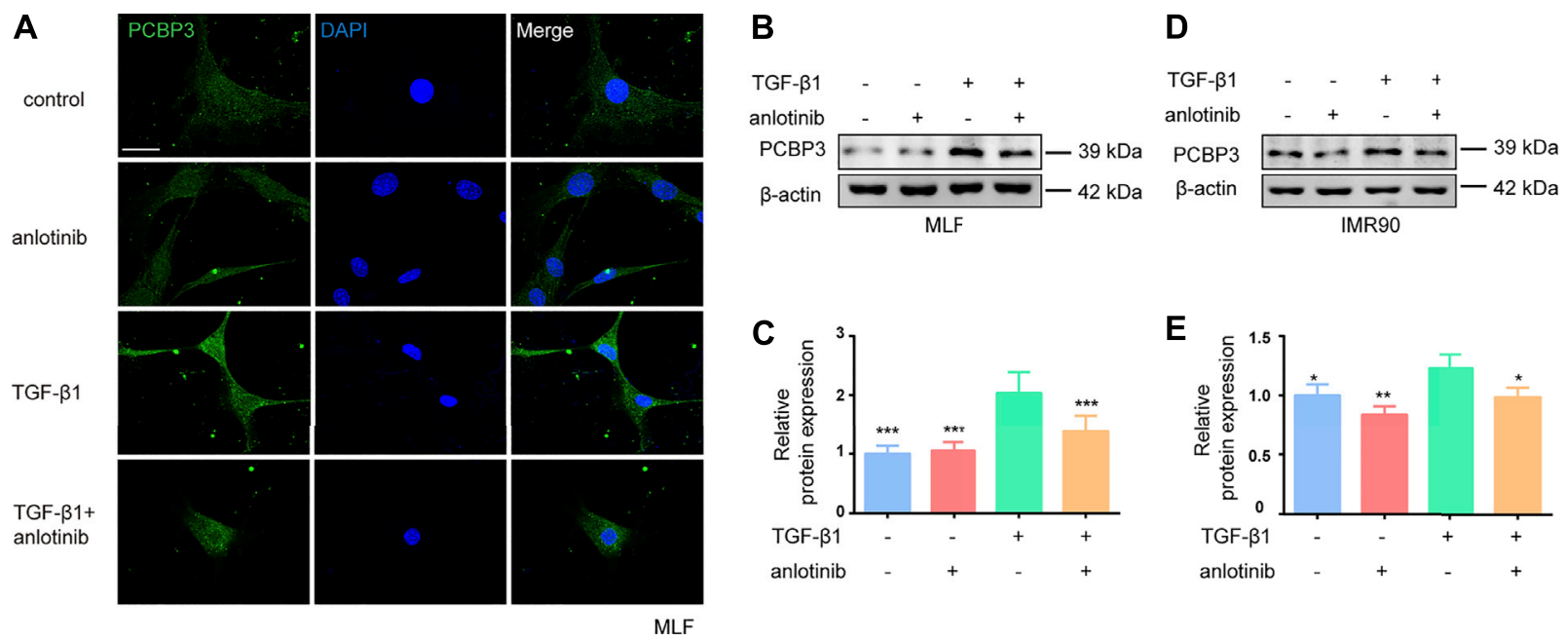

FIGURE 4 | Anlotinib represses PCBP3 expression levels during myofibroblast activation. (A) Immunofluorescence for PCBP3 (green) in mouse lung fibroblasts treated with anlotinib for $3 \mathrm{~h}$, followed by TGF- $\beta 1$ for an additional $24 \mathrm{~h}$. DAPI-stained nuclei (blue). Scale bar, $25 \mu \mathrm{m}$. (B) Western blots analysis of PCBP3 and $\beta$-actin in primary mouse lung fibroblasts. (C) Quantification for the indicated proteins (mean \pm SD, $n=3$ ). (D) The Western blots analysis of PCBP3 and $\beta$-actin in IMR90 cells treated with anlotinib for $3 \mathrm{~h}$, followed by TGF- $\beta 1$ for an additional $24 \mathrm{~h}$. (E) Quantification for the indicated proteins (mean $\pm \mathrm{SD}, \mathrm{n}=3$ ). ${ }^{\star} p<0.05,{ }^{\star \star} p<0.01,{ }^{\star \star \star} p<$ 0.001 VS TGF- $\beta 1$-treated group by ANOVA.

primary MLFs. Moreover, anlotinib inhibited the TGF- $\beta 1$ induced migration of fibroblasts (Figures 1I,J). These results were confirmed in the human IMR90 cell line (Figures 1K, L and Supplementary Figures S2A-D). These data indicate that anlotinib can repress myofibroblast activation and the profibrogenic phenotype in vitro.

\section{Anlotinib Inhibits PFKFB3-Driven Glycolysis in Lung Myofibroblasts}

To investigate the potential antifibrotic mechanisms of anlotinib, we estimated the most likely macromolecular targets of anlotinib and obtained 100 potential targets through SwissTargetPrediction (Table 2) (Gfeller et al., 2014). A total of 7,360 lung fibrosis-related targets were obtained from the GeneCards database (Table 3) (Safran et al., 2002). To clarify the interaction between potential anlotinib targets and lung fibrosis-related targets, the intersection of the targets was mapped by drawing a Venn diagram and constructing a target network (Figure 2A). Seventy-four common targets were shared between the potential anlotinib targets and lung fibrosis-related targets (Table 4). STRING (version 11.0) was used for proteinprotein interaction (PPI) analysis (Figure 2B) (Szklarczyk et al., 2019). Bioinformatics analysis data identified mitogenactivated protein kinase (MAPK) signaling pathway-related genes as the top hits among the 74 genes (Figure 2C). Given that the MAPK pathway is well recognized as a metabolic regulator and that many of these genes control metabolic processes (Figure 2D) (Ho et al., 2004; Papa et al., 2019; Hu et al., 2020; Wang F. et al., 2020), we first confirmed the presence of glycolytic alterations in lung myofibroblasts. We directly measured the levels of lactate and found that both intracellular and extracellular lactate levels in lung myofibroblasts treated with TGF- $\beta 1$ were significantly increased (Figures 2E,F). Consistent with the augmented glycolysis in lung myofibroblasts, these cells also demonstrated increased glucose consumption (Figure 2G). However, anlotinib treatment decreased the production and secretion of lactate and reduced the consumption of glucose (Figures 2E-G). Accordingly, extracellular acidification rate (ECAR) analysis indicated that treatment with TGF- $\beta 1$ increased glycolysis and glycolytic activity in primary MLFs, both of which were also reduced by anlotinib (Figures $\mathbf{2 H}$,I). To delineate the mechanisms by which anlotinib inhibits the augmented glycolysis observed in lung myofibroblasts, we assessed the expression of key glycolytic enzymes in these cells. We found that PFKFB3 was induced by TGF- $\beta 1$ in lung fibroblasts and that anlotinib significantly decreased its expression at the protein level (Figures 2J,K). PFKFB3 is not a rate-limiting glycolytic enzyme; instead, PFKFB3 catalyzes the conversion of fructose-6-phosphate to fructose-2,6bisphosphate, which is an allosteric activator of PFK1 and a potent stimulator of glycolysis (Atsumi et al., 2002; De Bock et al., 2013). Taken together, these data suggest that anlotinib can abrogate the PFKFB3-driven increase in glycolysis, participating in myofibroblast activation.

\section{PCBP3 Posttranscriptionally Increases PFKFB3 Expression by Promoting Its} Translation During Myofibroblast Activation Interestingly, the progressive upregulation of PFKFB3 during myofibroblast activation induced by TGF- $\beta 1$ that was observed at the protein level was not confirmed at the mRNA level, as measured by RT-PCR (Supplementary Figures S3A, B). These 


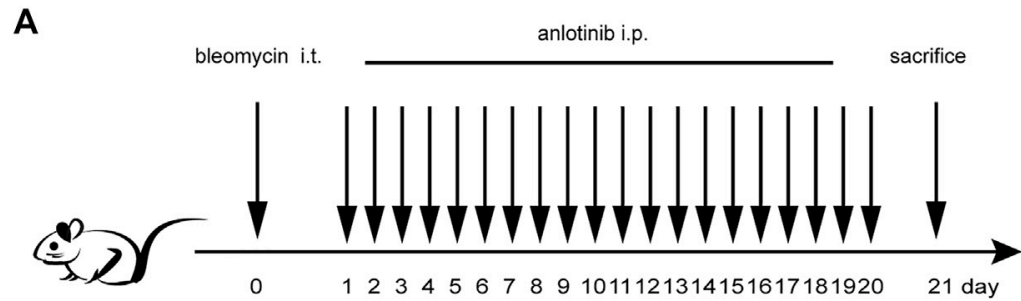

C

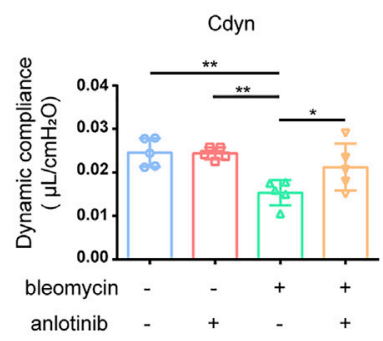

$\mathbf{F}$

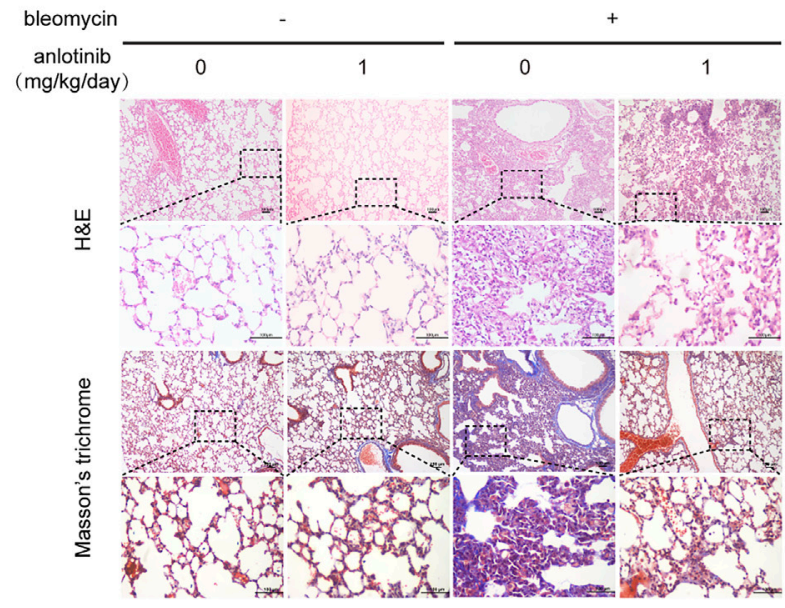

H

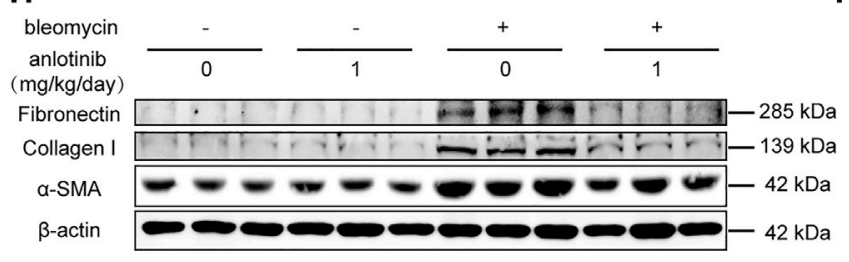

G

I
B

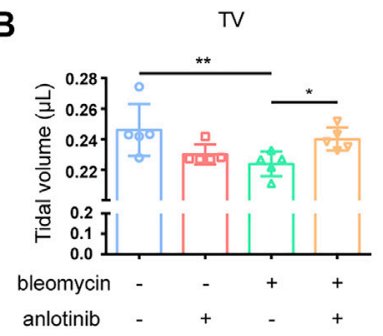

E

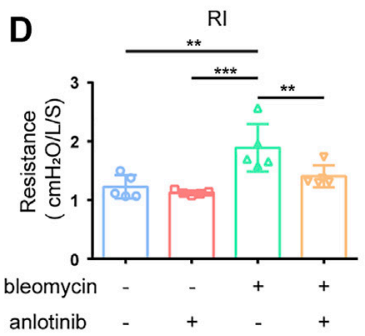

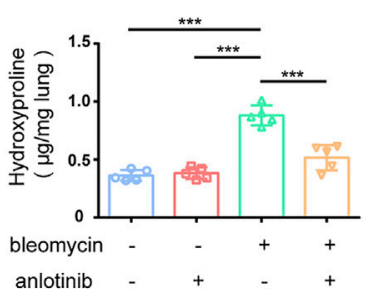

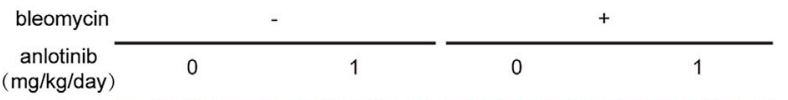
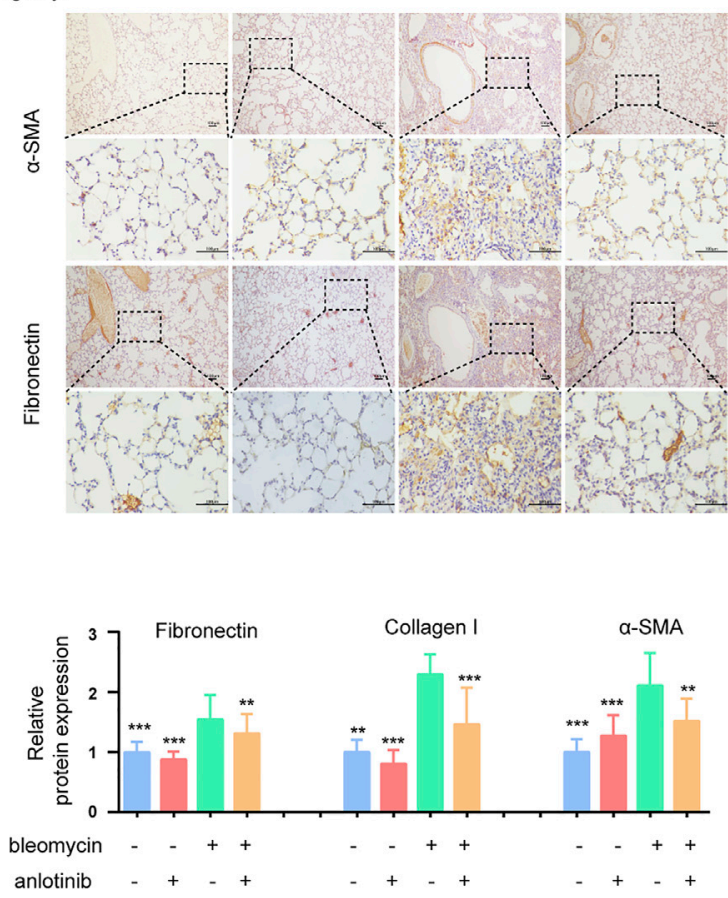

FIGURE 5 | Anlotinib attenuates bleomycin-induced pulmonary fibrosis. (A) Intervention dosing regimen of anlotinib in experimental mouse model of fibrosis. C57BL 6 mice were intraperitonealy injuected with $1 \mathrm{mg} / \mathrm{kg}$ of anlotinib or vehicle $(n=5-6$ per group) daily after bleomycin instillation. Lungs were harvested at 21 days for the following analyses. Analysis of tidal volume (TV) (B), dynamic compliance (Cdyn) (C), and lung resistance (RI) (D) (mean $\pm S D, n=5)$. (E) Hydroxyproline (HYP) contents in lung tissues from mice (mean $\pm S D, n=5$ ). Representative images show haematoxylin and eosin (H\&E), Masson's trichrome (F), $\alpha$-SMA and Fibronectin staining (G) of lung sections from the indicated groups of mice. Scale bars, $100 \mu \mathrm{m}$. (H) Western blot analysis of Fibronectin、Collagen I and $\alpha$-SMA, $\beta$-actin was used as a loading control. (I) Quantification of Fibronectin、Collagen I and $a$-SMA protein levels relative to $\beta$-actin is shown ( $m e a n \pm S D, n=6$ ). ${ }^{\star} p<0.05,{ }^{\star \star} p<0.01,{ }^{\star \star \star} p<0.001$ VS BLM-treated group by one-way ANOVA. 
A

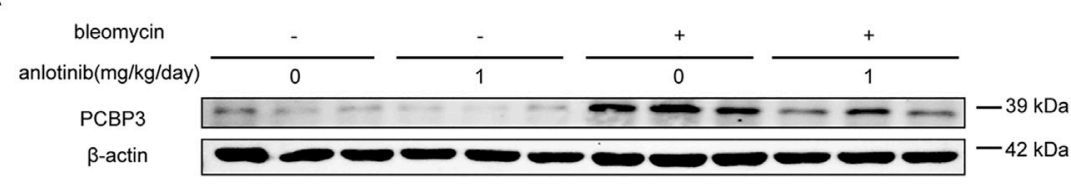

B

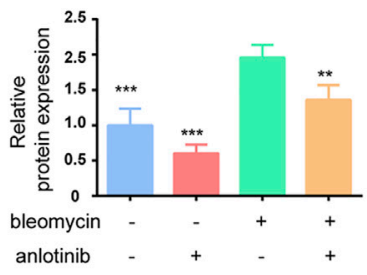

C bleomycin $+$ anlotinib (mg/kg/day) $\quad 0 \quad 1 \quad 0 \quad 1$
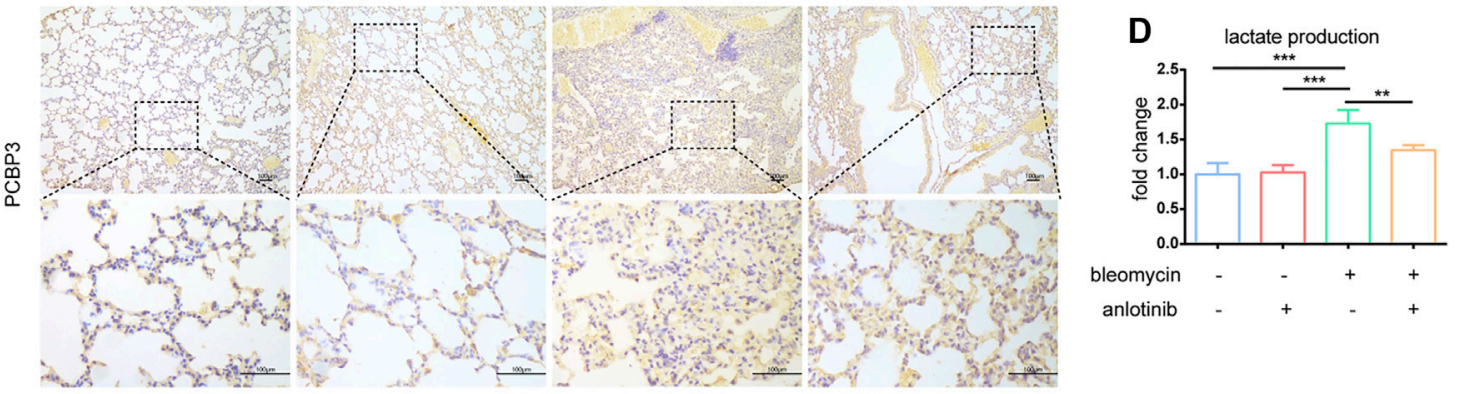

E

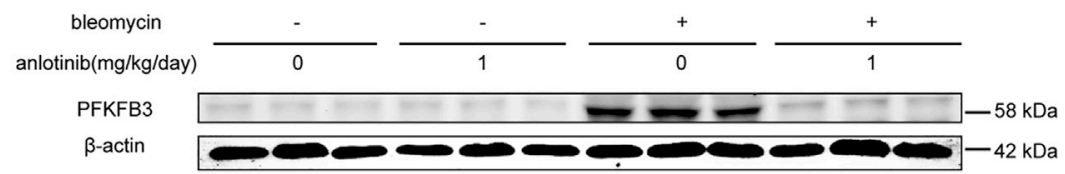

$\mathbf{F}$

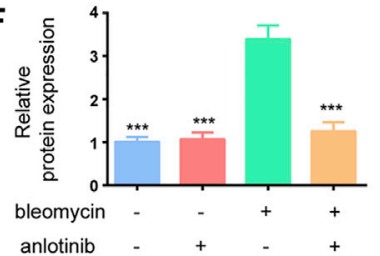

G bleomycin $-$

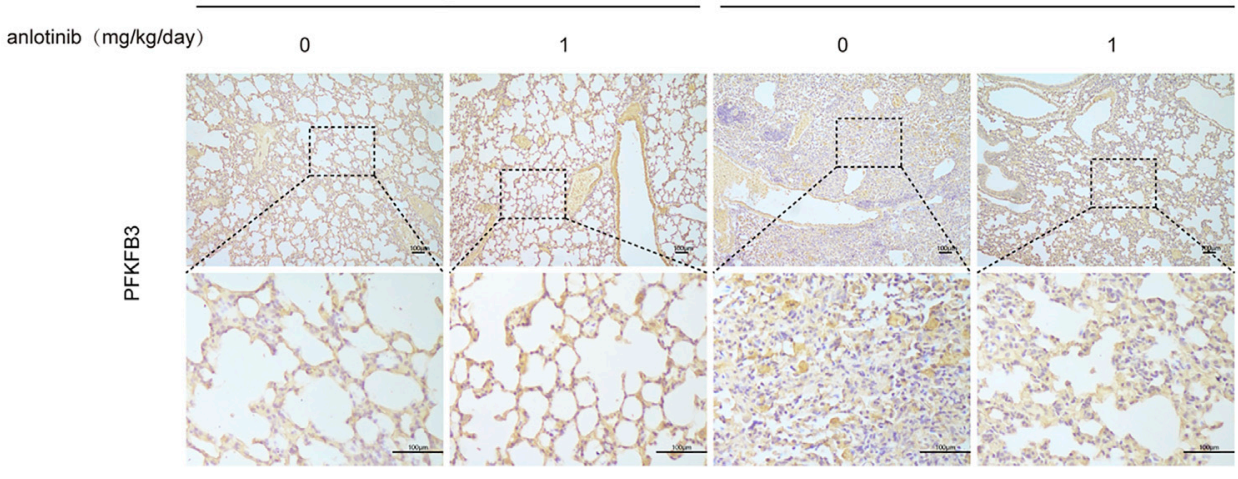

FIGURE 6 | Anlotinib decreases PCBP3 expression and inhibit the PFKFB3-driven glycolysis in fibrotic rodent lungs. (A) Intervention dosing regimen of anlotinib in experimental mouse model of fibrosis. C57BL/6 mice were intraperitonealy injuected with $1 \mathrm{mg} / \mathrm{kg}$ of anlotinib or vehicle (n = 5-6 per group) daily after bleomycin instillation. Lungs were harvested at 21 days. Western blot analysis of PCBP3, $\beta$-actin was used as a loading control ( $n=6)$. (B) Quantification of PCBP3 protein levels relative to $\beta$-actin is shown (mean $\pm S D, n=6$ ). (C) Representative images show PCBP3 staining of lung sections from the indicated groups of mice. Scale bars, $100 \mu \mathrm{m}$. (D) lactate contents in lung tissues from mice (mean $\pm \mathrm{SD}, \mathrm{n}=5$ ). (E) Western blot analysis of PFKFB3, $\beta$-actin was used as a loading control ( $\mathrm{n}=6$ ). (F) Quantification of PFKFB3 protein levels relative to $\beta$-actin is shown (mean $\pm S D, n=6$ ). (G) Representative images show PFKFB3 staining of lung sections from the indicated groups of mice. Scale bars, $100 \mu \mathrm{m} .{ }^{* \star} p<0.01,{ }^{\star \star *} p<0.001$ VS BLM-treated group by one-way ANOVA.

results indicate that TGF- $\beta 1$-induced overexpression does not require de novo transcription of PFKFB3. To further verify these findings, primary MLFs were incubated with cycloheximide to block new protein synthesis, and immunoblotting was used to measure PFKFB3 levels (Figure 3A). The half-life of PFKFB3 was not significantly altered, indicating that TGF- $\beta 1$ does not influence PFKFB3 protein stability. Therefore, we postulated that PFKFB3 upregulation is modulated through posttranscriptional mechanisms in this context. To verify this hypothesis, we used the online tool catRAPID to screen for potential proteins that may interact with PFKFB3 mRNA and identified that PCBP3 (Table 5) (Agostini et al., 2013; Livi et al., 
A

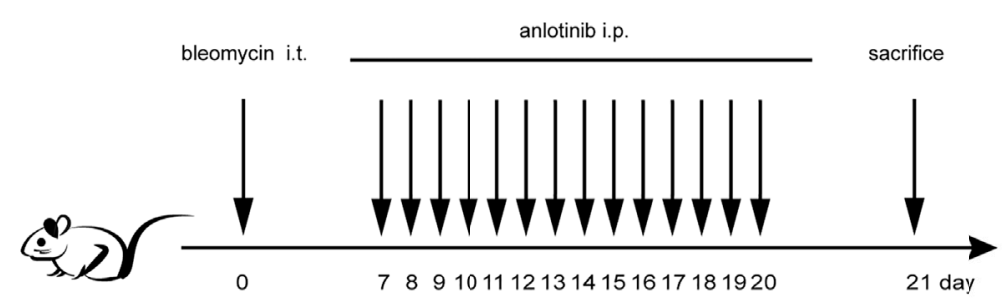

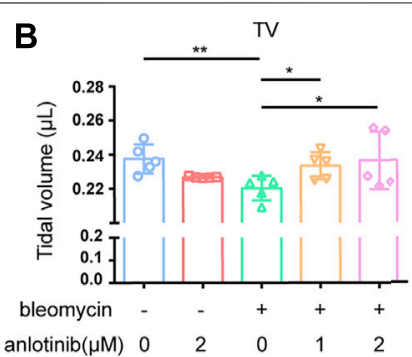

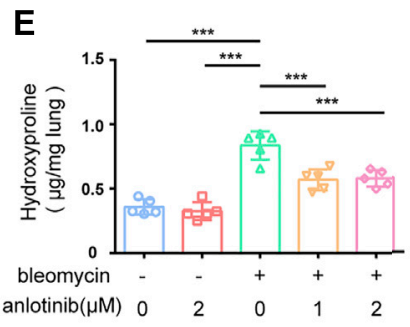

$\mathbf{F}$

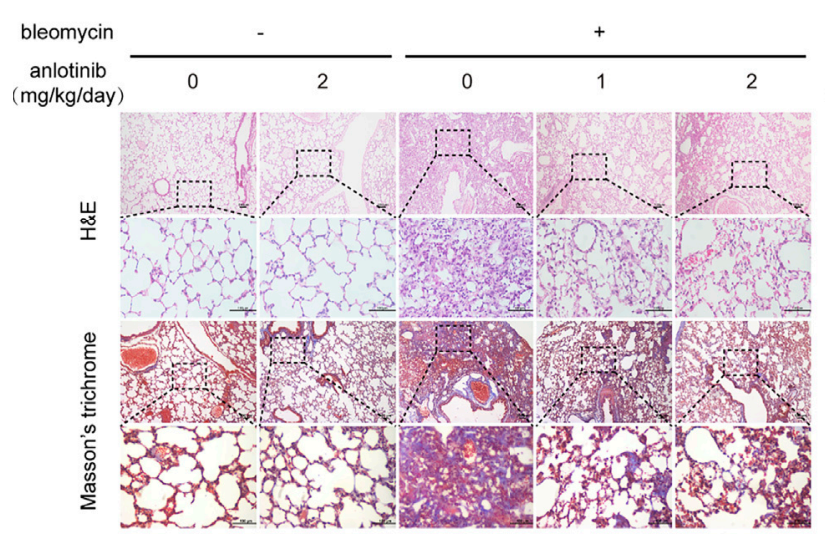

H

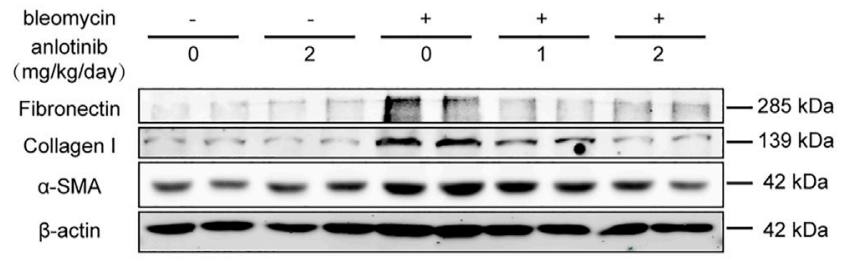

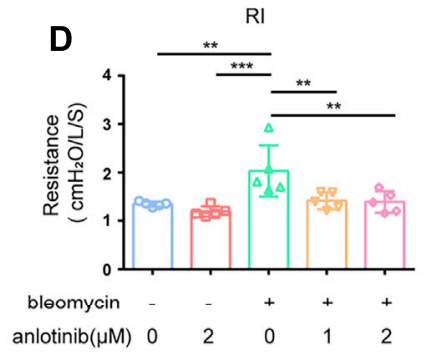

G

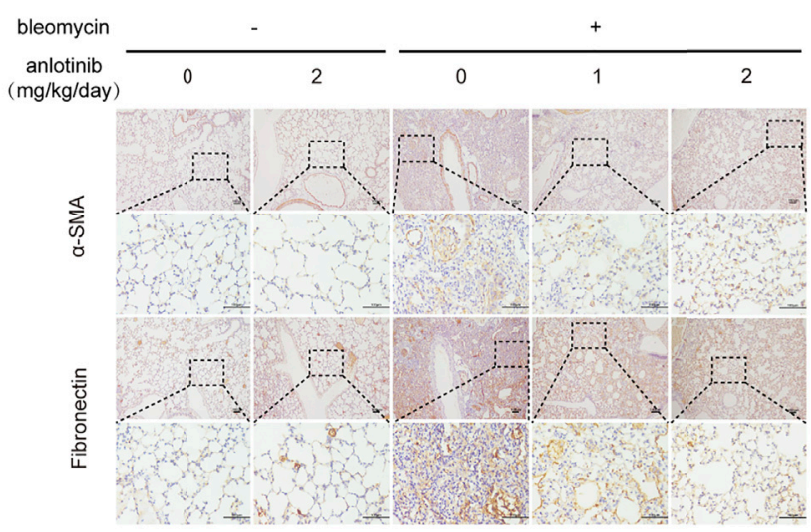

I

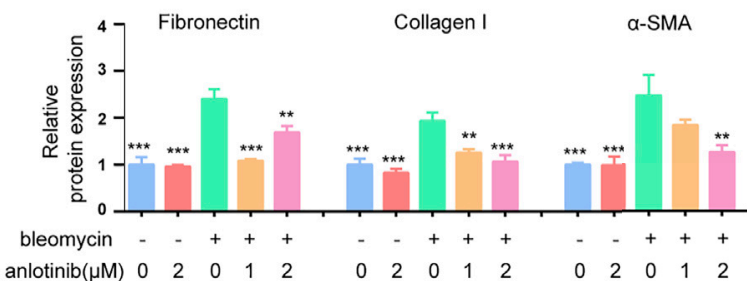

FIGURE 7|Anlotinib accelerates resolution of bleomycin-induced pulmonary fibrosis. (A) Intervention dosing regimen of anlotinib in established pulmonary fibrosis. Bleomycin instillation was used to induce fibrosis and no treatment was given during the first $7 \mathrm{~d}$. Then, mice were intraperitonealy injuected with $1 \mathrm{or} 2 \mathrm{mg} / \mathrm{kg}$ of anlotinib or vehicle ( $n=5-6$ per group) daily. Lungs were harvested at 21 days. Tidal volume (TV) (B), dynamic compliance (Cdyn) (C), and lung resistance (RI) (D) of mice were measured (mean $\pm S D, n=5$ ). (E) HYP contents in lung tissues from mice (mean $\pm S D, n=5$ ). Representative images show H\&E, Masson's trichrome (F), $\alpha$-SMA and Fibronectin staining (G) of lung sections from the indicated groups of mice. Scale bars, $100 \mu \mathrm{m}$. (H) Western blot analysis of Fibronectin, Collagen I and $\alpha$-SMA, $\beta$-actin was used as a loading control $(\mathrm{n}=4)$. (I) Quantification of Fibronectin、Collagen I and $\alpha$-SMA protein levels relative to $\beta$-actin is shown (mean \pm SD, $n=5)$. ${ }^{*} p<$ $0.05,{ }^{\star \star} p<0.01,{ }^{\star \star \star} p<0.001$ VS BLM-treated group by one-way ANOVA.

2016), a member of the PCBP family, has a high probability of directly interacting with PFKFB3 mRNA (Figure 3B) (Choi et al., 2007; Kang et al., 2012; Leidgens et al., 2013; Wang J. et al., 2020).
We comparatively analyzed the expression of PCBP3 after treatment with different doses of TGF- $\beta 1$ by immunoblot analysis and found that PCBP3 protein expression was 


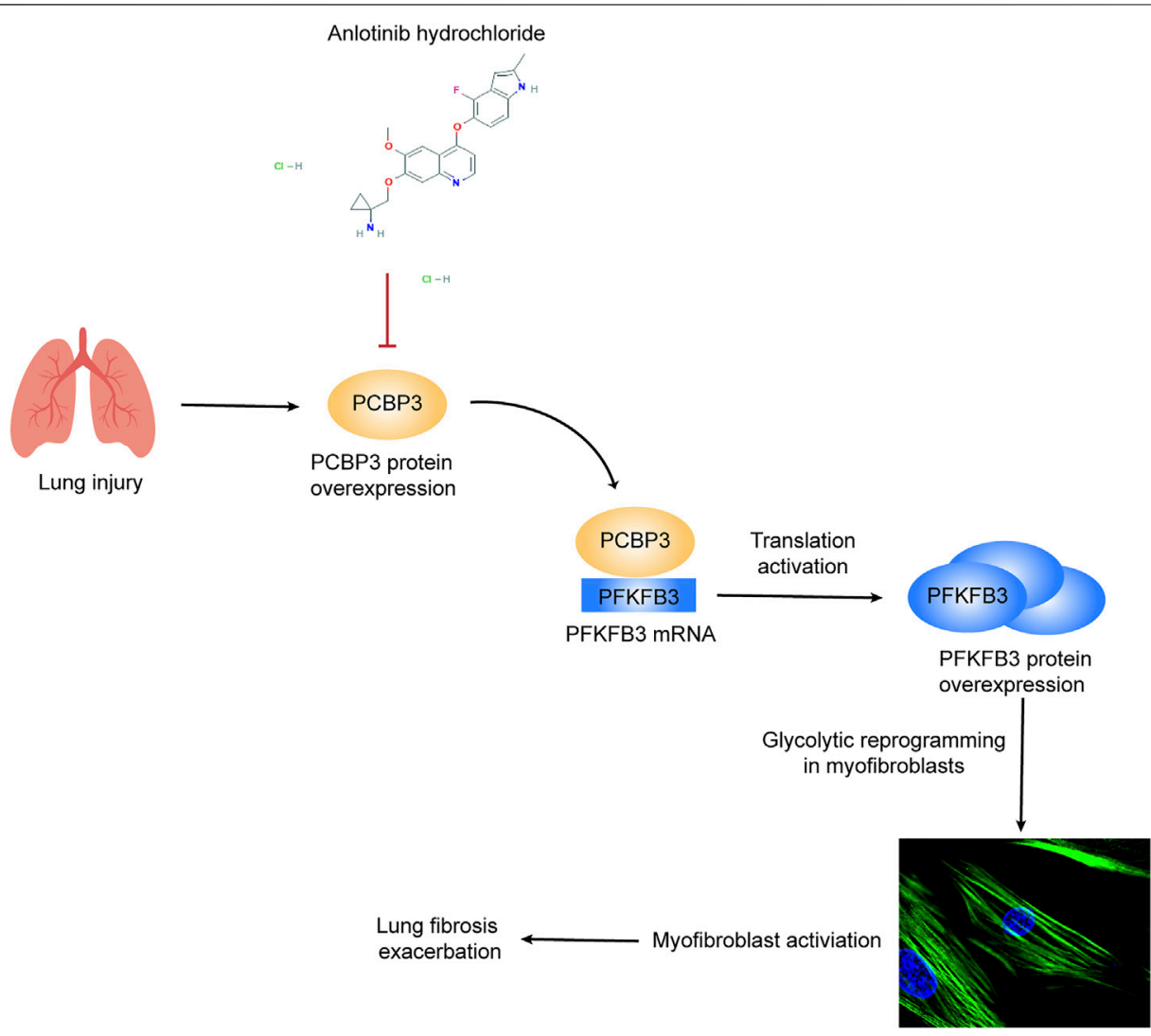

FIGURE 8| Schematic representation of PCBP3-PFKFB3-dependent glycolysis and the inhibitory effect of anlotinib on this pathway. Lung injury induces PCBP3 expression, which results in an increase in PFKFB3 expression by promoting its translation, resulting in the augmentation of glycolysis in lung fibroblasts. Glycolytic reprogramming participates in myofibroblast activation and furthers lung fibrosis. The tyrosine kinase inhibitor anlotinib inhibits PFKFB3-driven glycolysis by decreasing the expression of PCBP3, thereby suppressing myofibroblast activation and inhibiting the exacerbation of lung fibrosis.

TABLE 1 | List of primer sequences used in this study.

\begin{tabular}{|c|c|c|c|}
\hline Gene & Species & Forward primer & Reverse primer \\
\hline$\beta$-actin & Mus musculus & GGCTGTATTCCCCTCCATCG & CCAGTTGGTAACAATGCCATGT \\
\hline PFKFB3 & Mus musculus & CCCAGAGCCGGGTACAGAA & GGGGAGTTGGTCAGCTTCG \\
\hline
\end{tabular}

increased in primary MLFs after TGF- $\beta 1$ treatment (Figures 3C,D), which correlated with PFKFB3 overexpression. To better define the connection between РСВP3 function and PFKFB3, we performed RNA-protein coimmunoprecipitation (RIP) studies in primary MLFs transfected with FLAG-tagged PCBP3 (FLAG-PCBP3). An antibody targeting the FLAG protein was used to immunoprecipitate FLAG-PCBP3 and any interacting molecules from the cell lysates. Reverse transcription followed by PCR was then used to identify individual PFKFB3 mRNAs isolated with FLAG-PCBP3. We found that PFKFB3 transcripts were enriched by PCBP3 coimmunoprecipitation compared to control IgG coimmunoprecipitation (Figure 3E), demonstrating that PFKFB3 mRNA is indeed a direct target of PCBP3 in MLFs.
To test the possibility that PCBP3 may influence PFKFB3 translation, we performed polysome analysis in cells transfected with FLAG-PCBP3. Cytoplasmic lysates were fractionated through sucrose gradients to separate ribosomal subunits (40S and 60S), monosomes (80S) and progressively larger polysomes. RNA was extracted from each of the 12 fractions, and the levels of PFKFB3 and $\beta$-actin mRNA were quantified by quantitative RT-PCR. While PFKFB3 mRNA levels peaked in fraction 7 in control cells, the distribution of PFKFB3 mRNA shifted rightward when PCBP3 was overexpressed, peaking in fraction 9, indicating that PFKFB3 mRNA formed, on average, larger polysomes after PCBP3 overexpression (Figure 3F). The distribution of $\beta$-actin mRNA was not affected by PCBP3 overexpression. These results indicated that overexpression of 
TABLE 2 | Targets of anlotinib obtained through SwissTargetPrediction.

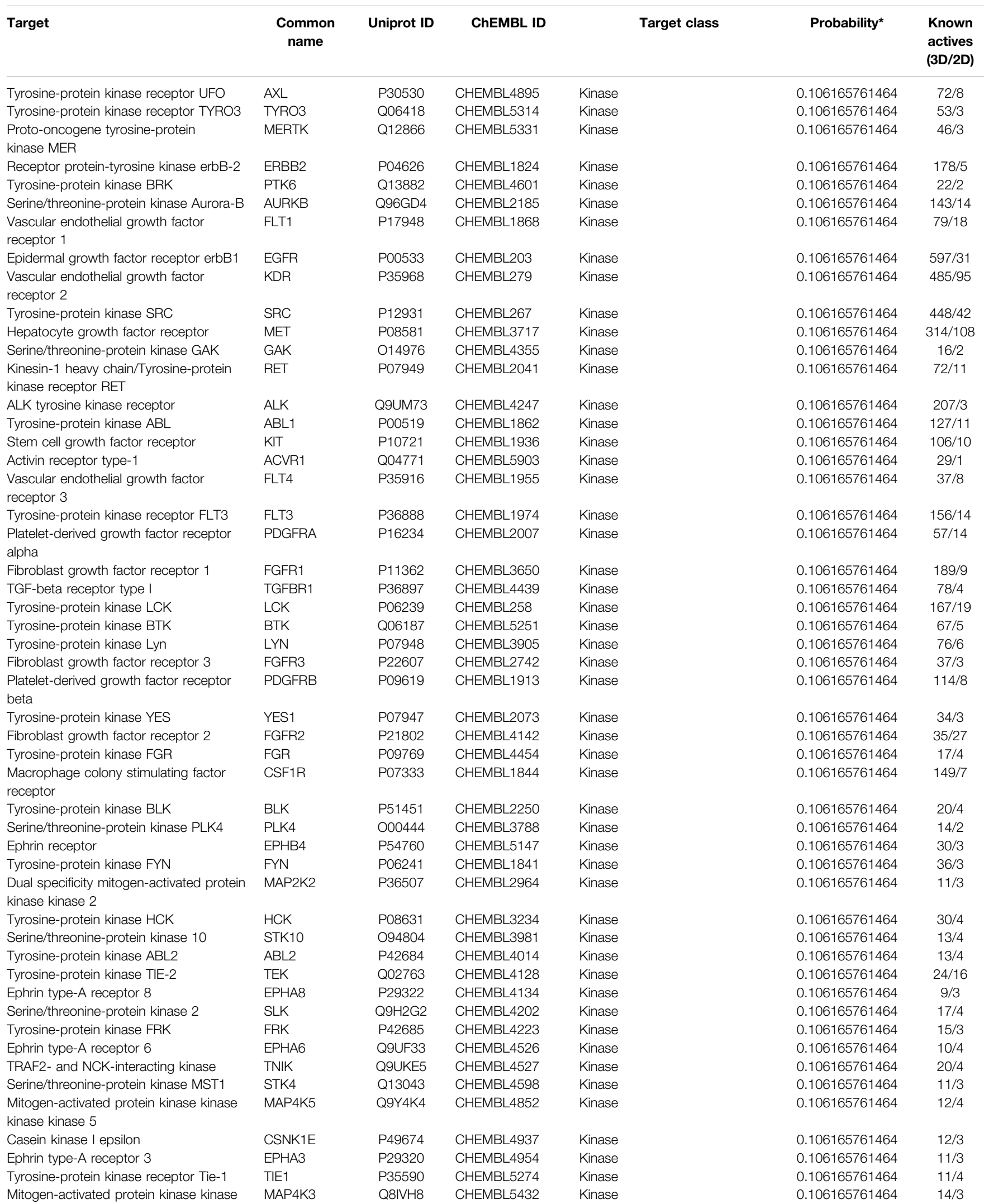


TABLE 2 | (Continued) Targets of anlotinib obtained through SwissTargetPrediction.

\begin{tabular}{|c|c|c|c|c|c|c|}
\hline Target & $\begin{array}{l}\text { Common } \\
\text { name }\end{array}$ & Uniprot ID & ChEMBL ID & Target class & Probability* & $\begin{array}{l}\text { Known } \\
\text { actives } \\
\text { (3D/2D) }\end{array}$ \\
\hline Serine/threonine-protein kinase SIK2 & SIK2 & Q9H0K1 & CHEMBL5699 & Kinase & 0.106165761464 & $12 / 3$ \\
\hline $\begin{array}{l}\text { Mitogen-activated protein kinase kinase } \\
\text { kinase kinase } 1\end{array}$ & MAP4K1 & Q92918 & CHEMBL5749 & Kinase & 0.106165761464 & $14 / 3$ \\
\hline Serine/threonine-protein kinase 33 & STK33 & Q9BYT3 & CHEMBL6005 & Kinase & 0.106165761464 & $16 / 4$ \\
\hline $\begin{array}{l}\text { Mitogen-activated protein kinase kinase } \\
\text { kinase kinase } 4\end{array}$ & MAP4K4 & O95819 & CHEMBL6166 & Kinase & 0.106165761464 & $17 / 4$ \\
\hline Serine/threonine-protein kinase TAO2 & TAOK2 & Q9UL54 & CHEMBL1075195 & Kinase & 0.106165761464 & $7 / 3$ \\
\hline Serine/threonine-protein kinase TAO3 & TAOK3 & Q9H2K8 & CHEMBL5701 & Kinase & 0.106165761464 & $12 / 2$ \\
\hline $\begin{array}{l}\text { Voltage-gated calcium channel alpha2/ } \\
\text { delta subunit } 1\end{array}$ & CACNA2D1 & P54289 & CHEMBL1919 & $\begin{array}{l}\text { Calcium channel auxiliary subunit } \\
\text { alpha2delta family }\end{array}$ & 0.106165761464 & $15 / 0$ \\
\hline $\begin{array}{l}\text { Voltage-gated calcium channel alpha2/ } \\
\text { delta subunit } 2\end{array}$ & CACNA2D2 & Q9NY47 & CHEMBL3896 & $\begin{array}{l}\text { Calcium channel auxiliary subunit } \\
\text { alpha2delta family }\end{array}$ & 0.106165761464 & $4 / 0$ \\
\hline Receptor protein-tyrosine kinase erbB-4 & ERBB4 & Q15303 & CHEMBL3009 & Kinase & 0.106165761464 & $29 / 3$ \\
\hline $\begin{array}{l}\text { Mitogen-activated protein kinase kinase } \\
\text { kinase } 8\end{array}$ & MAP3K8 & P41279 & CHEMBL4899 & Kinase & 0.106165761464 & $32 / 0$ \\
\hline $\begin{array}{l}\text { Serine/threonine-protein kinase/ } \\
\text { endoribonuclease IRE1 }\end{array}$ & ERN1 & O75460 & CHEMBL1163101 & Enzyme & 0.106165761464 & $18 / 1$ \\
\hline Macrophage-stimulating protein receptor & MST1R & Q04912 & CHEMBL2689 & Kinase & 0.106165761464 & $8 / 11$ \\
\hline Serine/threonine-protein kinase Aurora-C & AURKC & Q9UQB9 & CHEMBL3935 & Kinase & 0.106165761464 & $15 / 2$ \\
\hline Fibroblast growth factor receptor 4 & FGFR4 & P22455 & CHEMBL3973 & Kinase & 0.106165761464 & $15 / 2$ \\
\hline Ephrin type-A receptor 7 & EPHA7 & Q15375 & CHEMBL4602 & Kinase & 0.106165761464 & $7 / 3$ \\
\hline $\begin{array}{l}\text { Dual specificity mitogen-activated protein } \\
\text { kinase kinase } 5\end{array}$ & MAP2K5 & Q13163 & CHEMBL4948 & Kinase & 0.106165761464 & $11 / 4$ \\
\hline Serine/threonine-protein kinase RIPK2 & RIPK2 & 043353 & CHEMBL5014 & Kinase & 0.106165761464 & $6 / 4$ \\
\hline Discoidin domain-containing receptor 2 & DDR2 & Q16832 & CHEMBL5122 & Kinase & 0.106165761464 & $13 / 3$ \\
\hline Activin receptor type-1B & ACVR1B & P36896 & CHEMBL5310 & Kinase & 0.106165761464 & $6 / 1$ \\
\hline $\begin{array}{l}\text { Epithelial discoidin domain-containing } \\
\text { receptor } 1\end{array}$ & DDR1 & Q08345 & CHEMBL5319 & Kinase & 0.106165761464 & $14 / 4$ \\
\hline $\begin{array}{l}\text { Mitogen-activated protein kinase kinase } \\
\text { kinase kinase } 2\end{array}$ & MAP4K2 & Q12851 & CHEMBL5330 & Kinase & 0.106165761464 & $15 / 3$ \\
\hline Misshapen-like kinase 1 & MINK1 & Q8N4C8 & CHEMBL5518 & Kinase & 0.106165761464 & $14 / 4$ \\
\hline Leukocyte tyrosine kinase receptor & LTK & P29376 & CHEMBL5627 & Kinase & 0.106165761464 & $10 / 3$ \\
\hline Serine/threonine-protein kinase 35 & STK35 & Q8TDR2 & CHEMBL5651 & Kinase & 0.106165761464 & $9 / 4$ \\
\hline Ephrin type-A receptor 1 & EPHA1 & P21709 & CHEMBL5810 & Kinase & 0.106165761464 & $9 / 3$ \\
\hline Ephrin receptor & EPHB6 & O15197 & CHEMBL5836 & Unclassified protein & 0.106165761464 & $11 / 4$ \\
\hline Receptor tyrosine-protein kinase erbB-3 & ERBB3 & P21860 & CHEMBL5838 & Kinase & 0.106165761464 & $4 / 3$ \\
\hline Serine/threonine-protein kinase MST4 & STK26 & Q9P289 & CHEMBL5941 & Kinase & 0.106165761464 & $12 / 2$ \\
\hline $\begin{array}{l}\text { Eukaryotic translation initiation factor } \\
\text { 2-alpha kinase } 1\end{array}$ & EIF2AK1 & Q9BQI3 & CHEMBL6029 & Kinase & 0.106165761464 & $3 / 3$ \\
\hline SPS1/STE20-related protein kinase YSK4 & MAP3K19 & Q56UN5 & CHEMBL6191 & Kinase & 0.106165761464 & $15 / 4$ \\
\hline Serine/threonine-protein kinase AKT2 & AKT2 & P31751 & CHEMBL2431 & Kinase & 0.106165761464 & $318 / 0$ \\
\hline Protein kinase $\mathrm{C}$ gamma & PRKCG & P05129 & CHEMBL2938 & Kinase & 0.106165761464 & $38 / 0$ \\
\hline Serine/threonine-protein kinase AKT & AKT3 & Q9Y243 & CHEMBL4816 & Kinase & 0.106165761464 & $73 / 0$ \\
\hline Serine/threonine-protein kinase PIM1 & PIM1 & P11309 & CHEMBL2147 & Kinase & 0.106165761464 & $638 / 0$ \\
\hline Serine/threonine-protein kinase PIM2 & PIM2 & Q9P1W9 & CHEMBL4523 & Kinase & 0.106165761464 & $448 / 0$ \\
\hline Serine/threonine-protein kinase PIM3 & PIM3 & Q86V86 & CHEMBL5407 & Kinase & 0.106165761464 & $331 / 0$ \\
\hline Cyclin-dependent kinase 2/cyclin E1 & CCNE1 CDK2 & $\begin{array}{l}\text { P24864 } \\
\text { P24941 }\end{array}$ & CHEMBL1907605 & Kinase & 0.106165761464 & $74 / 0$ \\
\hline Tyrosine-protein kinase JAK1 & JAK1 & P23458 & CHEMBL2835 & Kinase & 0.106165761464 & $137 / 0$ \\
\hline Dipeptidyl peptidase VIII & DPP8 & Q6V1X1 & CHEMBL4657 & Protease & 0.106165761464 & $346 / 0$ \\
\hline Dipeptidyl peptidase IX & DPP9 & Q86TI2 & CHEMBL4793 & Protease & 0.106165761464 & $239 / 0$ \\
\hline Phosphodiesterase 4B & PDE4B & Q07343 & CHEMBL275 & Phosphodiesterase & 0.106165761464 & $43 / 0$ \\
\hline Protein kinase $\mathrm{C}$ iota & $\mathrm{PRKCl}$ & P41743 & CHEMBL2598 & Kinase & 0.106165761464 & $287 / 0$ \\
\hline Cyclin-dependent kinase 2 & CDK2 & P24941 & CHEMBL301 & Kinase & 0.106165761464 & $170 / 0$ \\
\hline Cyclin-dependent kinase 1 & CDK1 & P06493 & CHEMBL308 & Kinase & 0.106165761464 & $146 / 0$ \\
\hline Cyclin T1 & CCNT1 & 060563 & CHEMBL2108 & Other cytosolic protein & 0.106165761464 & $111 / 0$ \\
\hline Telomerase reverse transcriptase & TERT & 014746 & CHEMBL2916 & Enzyme & 0.106165761464 & $79 / 0$ \\
\hline Sodium/calcium exchanger 1 & SLC8A1 & P32418 & CHEMBL4076 & Electrochemical transporter & 0.106165761464 & $44 / 0$ \\
\hline $\begin{array}{l}\text { Gonadotropin-releasing hormone } \\
\text { receptor }\end{array}$ & GNRHR & P30968 & CHEMBL1855 & $\begin{array}{l}\text { Family A G protein-coupled } \\
\text { receptor }\end{array}$ & 0.106165761464 & $431 / 0$ \\
\hline Amine oxidase, copper containing & AOC3 & Q16853 & CHEMBL3437 & Enzyme & 0.106165761464 & $19 / 0$ \\
\hline
\end{tabular}


TABLE 3 | Lung fibrosis-related targets obtained from the GeneCards database.

\begin{tabular}{|c|c|c|c|c|c|c|c|}
\hline Number & Gene & Number & Gene & Number & Gene & Number & Gene \\
\hline 1 & CFTR & 335 & PDGFA & 669 & CPLANE1 & 1,003 & $\mathrm{HSPH} 1$ \\
\hline 2 & TGFB1 & 336 & MIR197 & 670 & MKI67 & 1,004 & MT-ATP6 \\
\hline 3 & TERT & 337 & MIRLET7B & 671 & TBX1 & 1,005 & MIR212 \\
\hline 4 & TP53 & 338 & MIR195 & 672 & $\mathrm{Pl} 3$ & 1,006 & CASP10 \\
\hline 5 & TNF & 339 & MIR96 & 673 & BMP4 & 1,007 & PDE5A \\
\hline 6 & SFTPC & 340 & CHI3L1 & 674 & PMS2 & 1,008 & SH2D1A \\
\hline 7 & EGFR & 341 & MIRLET7E & 675 & SLC7A7 & 1,009 & SCN5A \\
\hline 8 & IL6 & 342 & MIR16-1 & 676 & E2F1 & 1,010 & $\mathrm{RSPH} 4 \mathrm{~A}$ \\
\hline 9 & MUC5B & 343 & MIR199A1 & 677 & S100A1 & 1,011 & PIK3R2 \\
\hline 10 & RTEL1 & 344 & MIR210 & 678 & $\mathrm{TKT}$ & 1,012 & DNAH9 \\
\hline 11 & IL10 & 345 & MIR2OA & 679 & MYRF & 1,013 & PSMA7 \\
\hline 12 & SFTPB & 346 & MIR378A & 680 & LAMA5 & 1,014 & KIF3A \\
\hline 13 & SFTPA1 & 347 & THBD & 681 & COL2A1 & 1,015 & CYP3A5 \\
\hline 14 & ELN & 348 & DMBT1 & 682 & DEFB1 & 1,016 & LOC111674466 \\
\hline 15 & ABCA3 & 349 & MIR185 & 683 & RPL5 & 1,017 & ADM \\
\hline 16 & CAV1 & 350 & IL9 & 684 & SOD1 & 1,018 & PSMC3 \\
\hline 17 & IFNG & 351 & CFM1 & 685 & PLK1 & 1,019 & WDPCP \\
\hline 18 & MUC1 & 352 & CD79A & 686 & SCGB3A2 & 1,020 & MIR101-1 \\
\hline 19 & SFTPA2 & 353 & DYNC2LI1 & 687 & SLC9A3R1 & 1,021 & PRKCB \\
\hline 20 & SERPINA1 & 354 & NEK1 & 688 & IREB2 & 1,022 & IL13RA2 \\
\hline 21 & STAT3 & 355 & IQCB1 & 689 & LOC113664106 & 1,023 & MYH11 \\
\hline 22 & TERC & 356 & MIR204 & 690 & FADD & 1,024 & PRKG2 \\
\hline 23 & $\mathrm{CCN} 2$ & 357 & HLA-A & 691 & CYP3A4 & 1,025 & SUFU \\
\hline 24 & IL13 & 358 & IGF2 & 692 & HSPB1 & 1,026 & PIK3C2A \\
\hline 25 & TLR4 & 359 & FLNA & 693 & MAPK14 & 1,027 & PSMC5 \\
\hline 26 & PARN & 360 & $\mathrm{BCL} 2$ & 694 & CTSB & 1,028 & KCNQ1OT1 \\
\hline 27 & CTNNB1 & 361 & GSN & 695 & IGF2R & 1,029 & MIR133A1 \\
\hline 28 & CCR6 & 362 & MAP2K2 & 696 & BAP1 & 1,030 & GOPC \\
\hline 29 & AKT1 & 363 & BPIFA1 & 697 & GATA2 & 1,031 & TRAF2 \\
\hline 30 & MIR21 & 364 & MIR15A & 698 & MMP8 & 1,032 & TNFRSF6B \\
\hline 31 & NKX2-1 & 365 & EPHX1 & 699 & ITGAV & 1,033 & MIR139 \\
\hline 32 & MMP1 & 366 & HPS5 & 700 & PTX3 & 1,034 & LOC111674470 \\
\hline 33 & SMAD4 & 367 & TRAF3IP1 & 701 & MSLN & 1,035 & IGHMBP2 \\
\hline 34 & ACE & 368 & CFTR-AS1 & 702 & AFF4 & 1,036 & PSMA3 \\
\hline 35 & SPP1 & 369 & AP3B1 & 703 & CTCF & 1,037 & PSMC6 \\
\hline 36 & CXCL8 & 370 & GAPDH & 704 & ADA & 1,038 & GADD45B \\
\hline 37 & EGF & 371 & KRT19 & 705 & KITLG & 1,039 & FKRP \\
\hline 38 & FASLG & 372 & MIR107 & 706 & ZNF423 & 1,040 & DNAAF2 \\
\hline 39 & $\mathrm{CDH} 1$ & 373 & $\mathrm{CP}$ & 707 & IL12A & 1,041 & ERCC5 \\
\hline 40 & KRAS & 374 & HLA-B & 708 & PRKCA & 1,042 & E2F3 \\
\hline 41 & SERPINE1 & 375 & MMP12 & 709 & EGR1 & 1,043 & PIK3R3 \\
\hline 42 & BRAF & 376 & AGER & 710 & DLL4 & 1,044 & PRF1 \\
\hline 43 & SMAD3 & 377 & DDR1 & 711 & IFNA1 & 1,045 & IFNAR1 \\
\hline 44 & PRTN3 & 378 & TNNT2 & 712 & EZR & 1,046 & PF4 \\
\hline 45 & PIK3CA & 379 & CCL18 & 713 & LGALS3 & 1,047 & MIR27B \\
\hline 46 & IL1RN & 380 & MIR148B & 714 & AFP & 1,048 & VTN \\
\hline 47 & HMOX1 & 381 & MIR141 & 715 & TUBB2B & 1,049 & DNAJC5 \\
\hline 48 & IL1B & 382 & INS & 716 & EPCAM & 1,050 & BGLAP \\
\hline 49 & HLA-DRB1 & 383 & GLI3 & 717 & APOB & 1,051 & MIR455 \\
\hline 50 & FAM13A & 384 & JAK2 & 718 & SPPL2C & 1,052 & LOC111674471 \\
\hline 51 & FAS & 385 & EVC & 719 & CDK2 & 1,053 & CSF3R \\
\hline 52 & PTEN & 386 & HPS3 & 720 & GDF2 & 1,054 & VCL \\
\hline 53 & SFTPD & 387 & IL33 & 721 & EPO & 1,055 & NAGLU \\
\hline 54 & ITGAM & 388 & NOS2 & 722 & VCP & 1,056 & GUSB \\
\hline 55 & DSP & 389 & SLPI & 723 & HSPA8 & 1,057 & NEAT1 \\
\hline 56 & STN1 & 390 & MIR133B & 724 & ATP4A & 1,058 & TBX4 \\
\hline 57 & TGFBR1 & 391 & TCTN3 & 725 & $\mathrm{HBB}$ & 1,059 & PSMD1 \\
\hline 58 & $\mathrm{SRC}$ & 392 & TLR5 & 726 & SELE & 1,060 & PSMD12 \\
\hline 59 & CDKN2A & 393 & MUC4 & 727 & NAT2 & 1,061 & GAST \\
\hline 60 & ERBB2 & 394 & MIR93 & 728 & FGF10 & 1,062 & MIR99A \\
\hline 61 & CTLA4 & 395 & MIR18A & 729 & BMP7 & 1,063 & CREB1 \\
\hline 62 & NFE2L2 & 396 & SLC11A1 & 730 & ETS1 & 1,064 & TRPC6 \\
\hline 63 & MMP9 & 397 & PSMA6 & 731 & DEFB4A & 1,065 & EPAS1 \\
\hline 64 & MTOR & 398 & RNASE3 & 732 & PRDM10 & 1,066 & MIR125B1 \\
\hline
\end{tabular}


TABLE 3 | (Continued) Lung fibrosis-related targets obtained from the GeneCards database.

\begin{tabular}{|c|c|c|c|c|c|c|c|}
\hline Number & Gene & Number & Gene & Number & Gene & Number & Gene \\
\hline 65 & HRAS & 399 & SMAD2 & 733 & GJA1 & 1,067 & IFNGR1 \\
\hline 66 & TINF2 & 400 & ICAM1 & 734 & RPS6KB1 & 1,068 & PGR \\
\hline 67 & FGFR1 & 401 & TGFA & 735 & JAK3 & 1,069 & TLR1 \\
\hline 68 & COL1A1 & 402 & RPGR & 736 & TP63 & 1,070 & CD40 \\
\hline 69 & NPHP3 & 403 & ANXA5 & 737 & HNF1B & 1,071 & DLK1 \\
\hline 70 & $\mathrm{~F} 2$ & 404 & CXCR1 & 738 & BBS10 & 1,072 & FOS \\
\hline 71 & DPP9 & 405 & IL2 & 739 & ITGA2 & 1,073 & DNAL1 \\
\hline 72 & TGFB2 & 406 & GREM1 & 740 & HOTAIR & 1,074 & MAD1L1 \\
\hline 73 & ATP11A & 407 & CD274 & 741 & SGK1 & 1,075 & PSMD11 \\
\hline 74 & HFE & 408 & MIR142 & 742 & DNAAF1 & 1,076 & HBA2 \\
\hline 75 & PDGFRB & 409 & GSTP1 & 743 & DNMT1 & 1,077 & RAB11B \\
\hline 76 & ITGA3 & 410 & $\mathrm{PHOX} 2 \mathrm{~A}$ & 744 & DAB2 & 1,078 & CCKBR \\
\hline 77 & MIRLET7D & 411 & sos2 & 745 & $\mathrm{CDH} 2$ & 1,079 & CLCN3 \\
\hline 78 & MBL2 & 412 & LMNA & 746 & HJV & 1,080 & PPARA \\
\hline 79 & NOTCH1 & 413 & ENPP2 & 747 & PRKAA1 & 1,081 & $\mathrm{MB}$ \\
\hline 80 & MET & 414 & TOP1 & 748 & HSPA5 & 1,082 & GAS5-AS1 \\
\hline 81 & TIMP1 & 415 & APEX1 & 749 & CHUK & 1,083 & LOC111674474 \\
\hline 82 & SERPINH1 & 416 & CXCL9 & 750 & SKP2 & 1,084 & KCNJ1 \\
\hline 83 & SCNN1A & 417 & PLAU & 751 & ILK & 1,085 & KIAA0319L \\
\hline 84 & MMP2 & 418 & MIRLET7C & 752 & ADORA2B & 1,086 & PSMA2 \\
\hline 85 & ELANE & 419 & MIR30E & 753 & SST & 1,087 & PSMD3 \\
\hline 86 & VEGFA & 420 & MIR214 & 754 & CFLAR & 1,088 & LOC111674473 \\
\hline 87 & PLG & 421 & MIR486-1 & 755 & CCNB1 & 1,089 & ABCF2 \\
\hline 88 & MIR130A & 422 & KRT7 & 756 & ADCY10 & 1,090 & PSMD8 \\
\hline 89 & ADRB2 & 423 & TNFRSF13B & 757 & HDAC9 & 1,091 & MIR590 \\
\hline 90 & $\mathrm{KIT}$ & 424 & MIR106B & 758 & ARG1 & 1,092 & PSMD7 \\
\hline 91 & CC2D2A & 425 & MIR181A1 & 759 & BAK1 & 1,093 & RNF5 \\
\hline 92 & TGFBR2 & 426 & MTHFR & 760 & DICER1 & 1,094 & GLIS3 \\
\hline 93 & PDGFRA & 427 & BTNL2 & 761 & IKBKG & 1,095 & CHAT \\
\hline 94 & IL4 & 428 & PTPN11 & 762 & MYH6 & 1,096 & LOC111674476 \\
\hline 95 & NHP2 & 429 & KDR & 763 & COL4A3 & 1,097 & MIR23B \\
\hline 96 & STK11 & 430 & ELMOD2 & 764 & FGA & 1,098 & MIR130B \\
\hline 97 & NOP10 & 431 & STING1 & 765 & ABL1 & 1,099 & MIR151A \\
\hline 98 & ALOX5 & 432 & THY1 & 766 & GJA5 & 1,100 & LOC111674478 \\
\hline 99 & TMEM67 & 433 & MIR140 & 767 & ARHGAP31 & 1,101 & CD82 \\
\hline 100 & CCL2 & 434 & VCAM1 & 768 & FCGR3B & 1,102 & E2F2 \\
\hline 101 & MIR34C & 435 & CCR2 & 769 & SLC26A9 & 1,103 & RNF185 \\
\hline 102 & STAT1 & 436 & CDKN1A & 770 & LRBA & 1,104 & MIR423 \\
\hline 103 & ALB & 437 & STAT4 & 771 & PMM2 & 1,105 & DEFB103B \\
\hline 104 & HGF & 438 & CEP164 & 772 & $A C D$ & 1,106 & NFKB2 \\
\hline 105 & RPGRIP1L & 439 & MIR128-2 & 773 & CHIT1 & 1,107 & MIR186 \\
\hline 106 & NPHP1 & 440 & S100A9 & 774 & CDK6 & 1,108 & AFAP1-AS1 \\
\hline 107 & TSC2 & 441 & TLR3 & 775 & CSF1 & 1,109 & PSMC2 \\
\hline 108 & MDM2 & 442 & SERPINA3 & 776 & ABCG2 & 1,110 & ERLIN2 \\
\hline 109 & TTC21B & 443 & MIR25 & 777 & CASP1 & 1,111 & GADD45G \\
\hline 110 & EDN1 & 444 & CD44 & 778 & $\mathrm{P} 2 \mathrm{R} \times 7$ & 1,112 & CS \\
\hline 111 & WDR19 & 445 & MALAT1 & 779 & ASCL1 & 1,113 & CD22 \\
\hline 112 & CRP & 446 & COL3A1 & 780 & WWF & 1,114 & PSMB1 \\
\hline 113 & CCL11 & 447 & CD28 & 781 & PROM1 & 1,115 & LOC111674479 \\
\hline 114 & AGT & 448 & MIR23A & 782 & PDPN & 1,116 & LOC111674467 \\
\hline 115 & CCND1 & 449 & MIR19A & 783 & $\mathrm{PRODH}$ & 1,117 & $\mathrm{SDHB}$ \\
\hline 116 & COL1A2 & 450 & HAMP & 784 & ALG9 & 1,118 & LOC111674465 \\
\hline 117 & COPA & 451 & MIR429 & 785 & HOXD13 & 1,119 & PSMD14 \\
\hline 118 & CASP8 & 452 & MIR335 & 786 & TNFRSF10A & 1,120 & IFNB1 \\
\hline 119 & DKC1 & 453 & TTR & 787 & IL12B & 1,121 & PLAT \\
\hline 120 & ACTC1 & 454 & C2CD3 & 788 & BBS9 & 1,122 & PSMA5 \\
\hline 121 & FGFR2 & 455 & $\mathrm{NR} 1 \mathrm{H} 4$ & 789 & NR3C1 & 1,123 & NEB \\
\hline 122 & IL17A & 456 & G6PD & 790 & MIR122 & 1,124 & $\mathrm{CHGA}$ \\
\hline 123 & SCNN1B & 457 & MIR127 & 791 & ITGB3 & 1,125 & MIR187 \\
\hline 124 & ATM & 458 & TNNI3 & 792 & ERF & 1,126 & LOC113523647 \\
\hline 125 & MIR155 & 459 & CXCL1 & 793 & CCR5 & 1,127 & HSD3B7 \\
\hline 126 & $\mathrm{SHH}$ & 460 & MIR424 & 794 & ADIPOQ & 1,128 & LOC108491823 \\
\hline 127 & RB1 & 461 & IFT52 & 795 & TF & 1,129 & IL $4 \mathrm{R}$ \\
\hline 128 & CSF2 & 462 & $\mathrm{ZCCHC8}$ & 796 & RXRA & 1,130 & PSMB4 \\
\hline
\end{tabular}


TABLE 3 | (Continued) Lung fibrosis-related targets obtained from the GeneCards database.

\begin{tabular}{|c|c|c|c|c|c|c|c|}
\hline Number & Gene & Number & Gene & Number & Gene & Number & Gene \\
\hline 129 & CEP290 & 463 & AGTR2 & 797 & FAT4 & 1,131 & DRC1 \\
\hline 130 & FCGR2A & 464 & NSMCE3 & 798 & PSMD4 & 1,132 & MIR361 \\
\hline 131 & PKHD1 & 465 & TYR & 799 & UMOD & 1,133 & COL11A2 \\
\hline 132 & NPHP4 & 466 & ABCB4 & 800 & TMEM107 & 1,134 & MIR497 \\
\hline 133 & MIR200B & 467 & NOS3 & 801 & BLOC1S6 & 1,135 & SBDS \\
\hline 134 & MKS1 & 468 & LPAR1 & 802 & MMP14 & 1,136 & TLR6 \\
\hline 135 & SCNN1G & 469 & CXCR2 & 803 & PTK2B & 1,137 & MIR339 \\
\hline 136 & FAM111B & 470 & $\mathrm{ZIC3}$ & 804 & PIEZO2 & 1,138 & RECQL4 \\
\hline 137 & FN1 & 471 & LOC111674475 & 805 & CDK1 & 1,139 & DERL2 \\
\hline 138 & INVS & 472 & CCR7 & 806 & SIRT3 & 1,140 & SH2B3 \\
\hline 139 & STAT6 & 473 & ANKS6 & 807 & IL15 & 1,141 & GUCA2A \\
\hline 140 & WRAP53 & 474 & CALR & 808 & TAP1 & 1,142 & CCDC103 \\
\hline 141 & FGFR3 & 475 & TCTN1 & 809 & GATA6 & 1,143 & PCNA \\
\hline 142 & RET & 476 & MIR224 & 810 & EPOR & 1,144 & PSME2 \\
\hline 143 & NRAS & 477 & IGF1R & 811 & PVT1 & 1,145 & NCOR1 \\
\hline 144 & DDR2 & 478 & XRCC1 & 812 & MUSK & 1,146 & ТТС37 \\
\hline 145 & FBN1 & 479 & CD34 & 813 & ESR2 & 1,147 & PSMB5 \\
\hline 146 & OFD1 & 480 & EVC2 & 814 & MAP1B & 1,148 & PRKG1 \\
\hline 147 & MAP2K1 & 481 & CEACAM5 & 815 & MT-CYB & 1,149 & LEPR \\
\hline 148 & ENG & 482 & MIR338 & 816 & TRAF6 & 1,150 & TNC \\
\hline 149 & NEK8 & 483 & GATA4 & 817 & PKD1L1 & 1,151 & PTGS1 \\
\hline 150 & FGF2 & 484 & MIRLET7G & 818 & RBPJ & 1,152 & IFNA2 \\
\hline 151 & MUC5AC & 485 & SOD2 & 819 & DMD & 1,153 & DZIP1L \\
\hline 152 & NFKB1 & 486 & MIR191 & 820 & FABP4 & 1,154 & MIR296 \\
\hline 153 & RARB & 487 & CCR3 & 821 & CD80 & 1,155 & CD86 \\
\hline 154 & TNFRSF1A & 488 & CXCL5 & 822 & PSMA4 & 1,156 & MYCL \\
\hline 155 & IL5 & 489 & MYLK & 823 & IGHE & 1,157 & VPS45 \\
\hline 156 & APC & 490 & H2AC18 & 824 & EGFR-AS1 & 1,158 & GBE1 \\
\hline 157 & SMPD1 & 491 & GPC3 & 825 & DNMT3B & 1,159 & IL7R \\
\hline 158 & MPO & 492 & TMEM138 & 826 & MIR26A1 & 1,160 & CYP27A1 \\
\hline 159 & ACTA2 & 493 & MIR377 & 827 & FLT4 & 1,161 & PLA2G7 \\
\hline 160 & MIR126 & 494 & CCL22 & 828 & CCNA2 & 1,162 & NOTCH2 \\
\hline 161 & NOD2 & 495 & SLC34A2 & 829 & DNAI2 & 1,163 & CEACAM1 \\
\hline 162 & MIR17 & 496 & PTPN22 & 830 & TUG1 & 1,164 & MIR485 \\
\hline 163 & FGF7 & 497 & PKD2 & 831 & $\mathrm{IFIH1}$ & 1,165 & LOC113633876 \\
\hline 164 & IFT140 & 498 & DNAH5 & 832 & KATNIP & 1,166 & REG3A \\
\hline 165 & KRT18 & 499 & S100A4 & 833 & MMP3 & 1,167 & EPRS1 \\
\hline 166 & REN & 500 & BAX & 834 & KLF6 & 1,168 & LOC113633875 \\
\hline 167 & PDCD1 & 501 & THPO & 835 & BLOC1S3 & 1,169 & LOC113604967 \\
\hline 168 & VEGFC & 502 & MIR137 & 836 & SERPINB1 & 1,170 & ZEB1 \\
\hline 169 & IFT80 & 503 & FOXJ1 & 837 & GLA & 1,171 & FOXM1 \\
\hline 170 & SCGB1A1 & 504 & BCL2L1 & 838 & LPO & 1,172 & CASR \\
\hline 171 & BRCA2 & 505 & TRPV4 & 839 & $\mathrm{~F} 2 \mathrm{R}$ & 1,173 & TALDO1 \\
\hline 172 & $\mathrm{AHI}$ & 506 & CCR4 & 840 & BTK & 1,174 & MIR219A1 \\
\hline 173 & TCTN2 & 507 & CADM1 & 841 & socs3 & 1,175 & CCL26 \\
\hline 174 & BMPR2 & 508 & TMEM237 & 842 & COL4A2 & 1,176 & LOC113664107 \\
\hline 175 & RAF1 & 509 & LOC111674463 & 843 & NBAS & 1,177 & CLCN4 \\
\hline 176 & CXCR4 & 510 & GBA & 844 & CEP104 & 1,178 & SNHG1 \\
\hline 177 & KIAA0586 & 511 & $\mathrm{EZH} 2$ & 845 & MAGEA4 & 1,179 & LAMA2 \\
\hline 178 & HIF1A & 512 & SOX9 & 846 & DERL1 & 1,180 & TCF7 \\
\hline 179 & FARSB & 513 & MIR24-2 & 847 & AKT3 & 1,181 & TFRC \\
\hline 180 & TLR2 & 514 & SPARC & 848 & NPPA & 1,182 & PLCZ1 \\
\hline 181 & AGTR1 & 515 & S100A8 & 849 & BCL2L11 & 1,183 & POMC \\
\hline 182 & BMP6 & 516 & LTA & 850 & LAMA1 & 1,184 & ABCC3 \\
\hline 183 & CDK4 & 517 & MKKS & 851 & IL3 & 1,185 & CRYAB \\
\hline 184 & TMEM216 & 518 & HYDIN & 852 & ITGA5 & 1,186 & LOC110806263 \\
\hline 185 & RELA & 519 & GLI1 & 853 & CYP2D6 & 1,187 & MCM4 \\
\hline 186 & CSF3 & 520 & BIRC5 & 854 & DOCK6 & 1,188 & TNFSF13B \\
\hline 187 & CCL5 & 521 & MAPK3 & 855 & CANX & 1,189 & MIR149 \\
\hline 188 & ESR1 & 522 & PSMB8 & 856 & AXIN2 & 1,190 & PLA2G6 \\
\hline 189 & MIR223 & 523 & AP3D1 & 857 & SCARB2 & 1,191 & KNG1 \\
\hline 190 & FOXP3 & 524 & MIRLET7A3 & 858 & CDX2 & 1,192 & HOTTIP \\
\hline 191 & $T \mathrm{TN}$ & 525 & $\mathrm{IDH} 1$ & 859 & SLC9A3 & 1,193 & $\mathrm{AR}$ \\
\hline 192 & MARS1 & 526 & CYP2E1 & 860 & ICOS & 1,194 & PSMB2 \\
\hline
\end{tabular}


TABLE 3 | (Continued) Lung fibrosis-related targets obtained from the GeneCards database.

\begin{tabular}{|c|c|c|c|c|c|c|c|}
\hline Number & Gene & Number & Gene & Number & Gene & Number & Gene \\
\hline 193 & MAPK8 & 527 & TNFSF10 & 861 & PTGER4 & 1,195 & LSM1 \\
\hline 194 & MEG3 & 528 & PRKCD & 862 & SLC17A5 & 1,196 & NIPBL \\
\hline 195 & CCL3 & 529 & MIR181C & 863 & CXCR5 & 1,197 & PSMA8 \\
\hline 196 & HPS4 & 530 & CYCS & 864 & TCTEX1D2 & 1,198 & IL16 \\
\hline 197 & BRCA1 & 531 & IFT27 & 865 & MXRA5 & 1,199 & CCAT1 \\
\hline 198 & IL2RA & 532 & TUBB3 & 866 & FOXP1 & 1,200 & SPRY2 \\
\hline 199 & HPS1 & 533 & $\mathrm{HP}$ & 867 & MIR138-1 & 1,201 & RIPK1 \\
\hline 200 & MIR34A & 534 & ALMS1 & 868 & CLDN1 & 1,202 & PHKG2 \\
\hline 201 & MIR200C & 535 & NOX4 & 869 & MIR154 & 1,203 & MIR503 \\
\hline 202 & B9D1 & 536 & RYR1 & 870 & INSR & 1,204 & GSTT1 \\
\hline 203 & Dnase1 & 537 & TSLP & 871 & UCHL1 & 1,205 & PRKCl \\
\hline 204 & TSC1 & 538 & VDAC1 & 872 & $\mathrm{DCN}$ & 1,206 & AGL \\
\hline 205 & WDR35 & 539 & U2AF1 & 873 & XPNPEP3 & 1,207 & RAG2 \\
\hline 206 & WT1 & 540 & CAT & 874 & KRT13 & 1,208 & HNF1A-AS1 \\
\hline 207 & INPP5E & 541 & CALCA & 875 & COMT & 1,209 & CCAT2 \\
\hline 208 & MPL & 542 & DNAH11 & 876 & EDNRA & 1,210 & ERLIN1 \\
\hline 209 & MIR125A & 543 & NF1 & 877 & CA4 & 1,211 & MIR125B2 \\
\hline 210 & CSPP1 & 544 & PTK2 & 878 & HLA-DQA1 & 1,212 & MIR15B \\
\hline 211 & GRP & 545 & SP110 & 879 & BBS12 & 1,213 & CREBBP \\
\hline 212 & MIR144 & 546 & IL12RB1 & 880 & KRT8 & 1,214 & CTSL \\
\hline 213 & RTEL1-TNFRSF6B & 547 & NQO1 & 881 & CMA1 & 1,215 & NR5A1 \\
\hline 214 & SERPINC1 & 548 & GAA & 882 & AKR1B10 & 1,216 & MSR1 \\
\hline 215 & CD4 & 549 & MIR409 & 883 & LOC113633877 & 1,217 & UTP4 \\
\hline 216 & DYNC2H1 & 550 & VIP & 884 & CEP55 & 1,218 & MIR301A \\
\hline 217 & MIR145 & 551 & GPT & 885 & MAP2K4 & 1,219 & MUC7 \\
\hline 218 & FLT1 & 552 & MIR708 & 886 & CDK5 & 1,220 & CASC2 \\
\hline 219 & TNFRSF1B & 553 & NFKBIA & 887 & P2RY2 & 1,221 & ZNRD1ASP \\
\hline 220 & MIR29A & 554 & KEAP1 & 888 & NLRP3 & 1,222 & PLCG2 \\
\hline 221 & HLA-DQB1 & 555 & LOC111674477 & 889 & PSMC4 & 1,223 & MIR124-1 \\
\hline 222 & FHIT & 556 & CD36 & 890 & HSPA4 & 1,224 & MIR382 \\
\hline 223 & $\mathrm{H} 19$ & 557 & IGFBP3 & 891 & AVPR2 & 1,225 & LAMP1 \\
\hline 224 & PKD1 & 558 & NKX2-5 & 892 & RPS27A & 1,226 & CD69 \\
\hline 225 & sos1 & 559 & CEP83 & 893 & MIR375 & 1,227 & DANCR \\
\hline 226 & SPINK1 & 560 & BDNF & 894 & MIR33A & 1,228 & TP53COR1 \\
\hline 227 & MIR31 & 561 & ABCB11 & 895 & ATF6 & 1,229 & MYL3 \\
\hline 228 & IFT172 & 562 & FGFR4 & 896 & $\mathrm{RXRB}$ & 1,230 & CYSLTR2 \\
\hline 229 & MMP7 & 563 & CTSG & 897 & UBC & 1,231 & SELL \\
\hline 230 & CD8A & 564 & ITGB1 & 898 & NPC2 & 1,232 & LINC-ROR \\
\hline 231 & PDGFB & 565 & CSF2RA & 899 & CLCN2 & 1,233 & NOS1 \\
\hline 232 & SLC2A1 & 566 & DNAl1 & 900 & FOXE1 & 1,234 & IFT20 \\
\hline 233 & JUN & 567 & ARL3 & 901 & MIR132 & 1,235 & MIR10B \\
\hline 234 & BMP2 & 568 & MECP2 & 902 & HDGF & 1,236 & CD81 \\
\hline 235 & HMGB1 & 569 & CDKN1B & 903 & WNT7B & 1,237 & ANTXR1 \\
\hline 236 & ERBB3 & 570 & DNMT3A & 904 & SLC9A3R2 & 1,238 & PRSS2 \\
\hline 237 & MIR150 & 571 & $\mathrm{VHL}$ & 905 & $\mathrm{H} 2 \mathrm{AX}$ & 1,239 & SNHG2O \\
\hline 238 & PRSS1 & 572 & THBS1 & 906 & PRKAG2 & 1,240 & MIR95 \\
\hline 239 & MIR29C & 573 & YAP1 & 907 & SERPINB3 & 1,241 & GALC \\
\hline 240 & MIR146B & 574 & TIMP2 & 908 & LRP1B & 1,242 & DGCR5 \\
\hline 241 & $\mathrm{ABCC} 1$ & 575 & TOLLIP & 909 & DNAAF3 & 1,243 & HNMT \\
\hline 242 & BBS2 & 576 & KCNK3 & 910 & BCL10 & 1,244 & SLCO2A1 \\
\hline 243 & ABCB1 & 577 & NOTCH3 & 911 & RAG1 & 1,245 & $\mathrm{MLH} 1$ \\
\hline 244 & CXCL10 & 578 & RASSF1 & 912 & LAMA4 & 1,246 & PLA2G2A \\
\hline 245 & XIAP & 579 & SP1 & 913 & HLA-G & 1,247 & MME \\
\hline 246 & KIF21A & 580 & $\mathrm{RHOA}$ & 914 & PSMB3 & 1,248 & TYMS \\
\hline 247 & PIK3R1 & 581 & ABCC2 & 915 & SIRT1 & 1,249 & MIR198 \\
\hline 248 & BBS1 & 582 & IKBKB & 916 & MIRLET7A1 & 1,250 & JAK1 \\
\hline 249 & IRF1 & 583 & GZMB & 917 & PLA2G1B & 1,251 & PDE4D \\
\hline 250 & IL1A & 584 & LEP & 918 & KDM4C & 1,252 & LAMC2 \\
\hline 251 & PTPRC & 585 & BBS5 & 919 & MUC6 & 1,253 & $\mathrm{AHR}$ \\
\hline 252 & HLA-DPB1 & 586 & APOE & 920 & TUBB1 & 1,254 & TPM1 \\
\hline 253 & ERCC6 & 587 & NHLRC2 & 921 & SKIV2L & 1,255 & MT-CO2 \\
\hline 254 & STX1A & 588 & NPPB & 922 & TPM2 & 1,256 & ASCC1 \\
\hline 255 & SETD2 & 589 & SYP & 923 & CCDC40 & 1,257 & EOGT \\
\hline 256 & CCL17 & 590 & ACTB & 924 & TET2 & 1,258 & CCL7 \\
\hline
\end{tabular}


TABLE 3 | (Continued) Lung fibrosis-related targets obtained from the GeneCards database.

\begin{tabular}{|c|c|c|c|c|c|c|c|}
\hline Number & Gene & Number & Gene & Number & Gene & Number & Gene \\
\hline 257 & $\mathrm{IDH} 2$ & 591 & PSMA1 & 925 & TRIP11 & 1,259 & TRPM4 \\
\hline 258 & CXCL12 & 592 & PTCH1 & 926 & ITGA2B & 1,260 & GPSM2 \\
\hline 259 & MIR27A & 593 & LOXL2 & 927 & ENO2 & 1,261 & TARS1 \\
\hline 260 & GSTM1 & 594 & CEP41 & 928 & EIF2AK3 & 1,262 & TPM3 \\
\hline 261 & DCTN4 & 595 & MYPN & 929 & RSPH9 & 1,263 & CD14 \\
\hline 262 & PRKN & 596 & CR1 & 930 & MIR193A & 1,264 & MIR216A \\
\hline 263 & CXCR3 & 597 & ERCC1 & 931 & PXN & 1,265 & CTAG1B \\
\hline 264 & MIR200A & 598 & IGFBP5 & 932 & DNAAF5 & 1,266 & MIR22HG \\
\hline 265 & ARL13B & 599 & MGMT & 933 & LAT & 1,267 & MIR10A \\
\hline 266 & PTGS2 & 600 & VIM & 934 & $\mathrm{RSPH} 1$ & 1,268 & PCAT1 \\
\hline 267 & MIR148A & 601 & ENO1 & 935 & CDKN2B-AS1 & 1,269 & SNHG15 \\
\hline 268 & MYC & 602 & NLRC4 & 936 & ADORA1 & 1,270 & BANCR \\
\hline 269 & IGF1 & 603 & PIK3CG & 937 & RAD51 & 1,271 & PSAP \\
\hline 270 & IL18 & 604 & MYH7 & 938 & DIABLO & 1,272 & IL11 \\
\hline 271 & CYP1A1 & 605 & F13A1 & 939 & TFR2 & 1,273 & MIR362 \\
\hline 272 & NEK9 & 606 & WNT4 & 940 & RSPO2 & 1,274 & UCA1 \\
\hline 273 & LOX & 607 & NME1 & 941 & C4A & 1,275 & UBE2L3 \\
\hline 274 & MIR30D & 608 & CD63 & 942 & $\mathrm{IF} \mid 27$ & 1,276 & FBLN5 \\
\hline 275 & MIR146A & 609 & RPGRIP1 & 943 & MIR29B1 & 1,277 & GC \\
\hline 276 & IFT122 & 610 & ATP8B1 & 944 & HSPD1 & 1,278 & TP73-AS1 \\
\hline 277 & B9D2 & 611 & GNAS & 945 & CCDC39 & 1,279 & PPBP \\
\hline 278 & KCNQ1 & 612 & TUBB & 946 & PDE4A & 1,280 & LINC00473 \\
\hline 279 & CYP2A6 & 613 & IFRD1 & 947 & TRIM21 & 1,281 & SOX2-OT \\
\hline 280 & MIR483 & 614 & CASP9 & 948 & PLCG1 & 1,282 & MIR181B1 \\
\hline 281 & MIR183 & 615 & LAMP2 & 949 & IL1RL1 & 1,283 & XIST \\
\hline 282 & IL1R1 & 616 & HDAC2 & 950 & BBIP1 & 1,284 & MIR129-1 \\
\hline 283 & SDCCAG8 & 617 & ANXA1 & 951 & MIR196A1 & 1,285 & $\mathrm{PRL}$ \\
\hline 284 & PTRH2 & 618 & IFT74 & 952 & $\mathrm{BAD}$ & 1,286 & MIR193B \\
\hline 285 & MIR182 & 619 & ROS1 & 953 & MYBPC3 & 1,287 & NR3C2 \\
\hline 286 & CDKN3 & 620 & CLEC7A & 954 & ARAF & 1,288 & MYL1 \\
\hline 287 & GUCY2C & 621 & AKT2 & 955 & VDR & 1,289 & SDC1 \\
\hline 288 & MIR222 & 622 & WRN & 956 & MAGEA1 & 1,290 & MIR24-1 \\
\hline 289 & LOC111674472 & 623 & DTNBP1 & 957 & TAC1 & 1,291 & $\mathrm{PHB}$ \\
\hline 290 & KIF7 & 624 & CD19 & 958 & IDUA & 1,292 & MYL2 \\
\hline 291 & FLNC & 625 & SMARCA4 & 959 & EPX & 1,293 & APOA1 \\
\hline 292 & PPARG & 626 & ANGPT2 & 960 & ASXL1 & 1,294 & SNHG12 \\
\hline 293 & XRCC3 & 627 & PARP1 & 961 & MAGEA3 & 1,295 & CEP57 \\
\hline 294 & SNAI1 & 628 & BBS7 & 962 & RAC1 & 1,296 & IL6R \\
\hline 295 & POSTN & 629 & MIF & 963 & GATA1 & 1,297 & SERPINF2 \\
\hline 296 & MIR192 & 630 & SELP & 964 & GAS5 & 1,298 & CALB2 \\
\hline 297 & JAG1 & 631 & HSPG2 & 965 & MIR9-1 & 1,299 & MIR152 \\
\hline 298 & CD40LG & 632 & ATP12A & 966 & RYR2 & 1,300 & ADK \\
\hline 299 & DYNC2I1 & 633 & HSP90AA1 & 967 & $\mathrm{JPH} 2$ & 1,301 & NRG1 \\
\hline 300 & ACVRL1 & 634 & CHRM3 & 968 & $\mathrm{RIOX} 2$ & 1,302 & MIR501 \\
\hline 301 & MIR221 & 635 & MVP & 969 & LOC111674464 & 1,303 & GPRC5A \\
\hline 302 & IFT43 & 636 & DCDC2 & 970 & TNFAIP3 & 1,304 & LZTR1 \\
\hline 303 & DES & 637 & ERCC2 & 971 & PIK3CB & 1,305 & TLR7 \\
\hline 304 & MIR22 & 638 & PPP2R1B & 972 & $\mathrm{DHCR} 7$ & 1,306 & POT1 \\
\hline 305 & TNFRSF10B & 639 & TYMP & 973 & C1S & 1,307 & EP300 \\
\hline 306 & IRF5 & 640 & CLCA1 & 974 & SNAI2 & 1,308 & $\mathrm{FBL}$ \\
\hline 307 & ALK & 641 & OGG1 & 975 & ERBB4 & 1,309 & PLOD2 \\
\hline 308 & CEP120 & 642 & MCL1 & 976 & ACVR1 & 1,310 & DLL1 \\
\hline 309 & MIR451A & 643 & $\mathrm{CCN} 4$ & 977 & NPC1 & 1,311 & TOP2A \\
\hline 310 & DYNC2I2 & 644 & F3 & 978 & LNX1 & 1,312 & MAGEC2 \\
\hline 311 & CASP3 & 645 & STAT5B & 979 & GRB2 & 1,313 & MIR499A \\
\hline 312 & CCL4 & 646 & FUZ & 980 & TFAP2B & 1,314 & ENSG00000266919 \\
\hline 313 & HPS6 & 647 & LBR & 981 & SLC6A4 & 1,315 & TNFRSF11B \\
\hline 314 & MIR143 & 648 & CXCL2 & 982 & IFT88 & 1,316 & HOXA11-AS \\
\hline 315 & ICOSLG & 649 & PLAUR & 983 & NPHS1 & 1,317 & RASGRP1 \\
\hline 316 & CLCA4 & 650 & ASAH1 & 984 & MAP2K7 & 1,318 & SPRY4-IT1 \\
\hline 317 & HLA-DPA1 & 651 & $\mathrm{BPI}$ & 985 & PSMD2 & 1,319 & FIP1L1 \\
\hline 318 & FOXF1 & 652 & NPM1 & 986 & DNAH8 & 1,320 & GSR \\
\hline 319 & BIRC3 & 653 & ACTA1 & 987 & B2M & 1,321 & CST3 \\
\hline 320 & SMAD7 & 654 & ANGPT1 & 988 & INTU & 1,322 & LTBP4 \\
\hline
\end{tabular}

(Continued on following page) 
TABLE 3 | (Continued) Lung fibrosis-related targets obtained from the GeneCards database.

\begin{tabular}{|c|c|c|c|c|c|c|c|}
\hline Number & Gene & Number & Gene & Number & Gene & Number & Gene \\
\hline 321 & MIR203A & 655 & GGT1 & 989 & ENTPD1 & 1,323 & ZFAS1 \\
\hline 322 & MIR30A & 656 & CAMP & 990 & PRSS8 & 1,324 & F5 \\
\hline 323 & MIR324 & 657 & SOD3 & 991 & CCNE1 & 1,325 & STMN1 \\
\hline 324 & MIR199B & 658 & F2RL3 & 992 & LRRC56 & 1,326 & AIRE \\
\hline 325 & ACP5 & 659 & TEK & 993 & MAР3К8 & 1,327 & RETN \\
\hline 326 & MIR205 & 660 & LTF & 994 & $\mathrm{SHC1}$ & 1,328 & NTS \\
\hline 327 & TP73 & 661 & MT-CO1 & 995 & CCDC114 & 1,329 & KRT5 \\
\hline 328 & TLR9 & 662 & LIPA & 996 & $\mathrm{ACHE}$ & 1,330 & F2RL1 \\
\hline 329 & MAPK1 & 663 & WNT3 & 997 & TBX20 & 1,331 & TNFSF11 \\
\hline 330 & CLCN5 & 664 & GDF1 & 998 & AURKB & 1,332 & COL4A5 \\
\hline 331 & TMEM231 & 665 & SLC4OA1 & 999 & ASL & 1,333 & PIK3CD \\
\hline 332 & BBS4 & 666 & GLIS2 & 1,000 & MIR30C1 & 1,334 & FGF9 \\
\hline 333 & RMRP & 667 & AREG & 1,001 & IL2RB & 1,335 & KRT20 \\
\hline 334 & TGFB3 & 668 & CDKN2B & 1,002 & NCF2 & & \\
\hline
\end{tabular}

TABLE 4 | Common targets shared between the potential anlotinib targets and lung fibrosis-related targets.

\begin{tabular}{|c|c|c|c|}
\hline Number & Gene & Number & Gene \\
\hline 1 & $A X L$ & 38 & EPHA3 \\
\hline 2 & MERTK & 39 & TIE1 \\
\hline 3 & ERBB2 & 40 & CACNA2D1 \\
\hline 4 & AURKB & 41 & ERBB4 \\
\hline 5 & FLT1 & 42 & MAР3К8 \\
\hline 6 & EGFR & 43 & ERN1 \\
\hline 7 & KDR & 44 & MST1R \\
\hline 8 & SRC & 45 & FGFR4 \\
\hline 9 & MET & 46 & EPHA7 \\
\hline 10 & RET & 47 & MAP2K5 \\
\hline 11 & ALK & 48 & RIPK2 \\
\hline 12 & ABL1 & 49 & DDR2 \\
\hline 13 & KIT & 50 & ACVR1B \\
\hline 14 & ACVR1 & 51 & DDR1 \\
\hline 15 & FLT4 & 52 & MAP4K2 \\
\hline 16 & FLT3 & 53 & EPHA1 \\
\hline 17 & PDGFRA & 54 & EPHB6 \\
\hline 18 & FGFR1 & 55 & ERBB3 \\
\hline 19 & TGFBR1 & 56 & ElF2AK1 \\
\hline 20 & BTK & 57 & MAP3K19 \\
\hline 21 & LYN & 58 & AKT2 \\
\hline 22 & FGFR3 & 59 & PRKCG \\
\hline 23 & PDGFRB & 60 & AKT3 \\
\hline 24 & YES1 & 61 & PIM1 \\
\hline 25 & FGFR2 & 62 & PIM2 \\
\hline 26 & FGR & 63 & JAK1 \\
\hline 27 & CSF1R & 64 & DPP8 \\
\hline 28 & BLK & 65 & DPP9 \\
\hline 29 & PLK4 & 66 & PDE4B \\
\hline 30 & FYN & 67 & PRKCl \\
\hline 31 & MAP2K2 & 68 & CDK2 \\
\hline 32 & $\mathrm{HCK}$ & 69 & CDK1 \\
\hline 33 & STK10 & 70 & CCNT1 \\
\hline 34 & ABL2 & 71 & TERT \\
\hline 35 & TEK & 72 & SLC8A1 \\
\hline 36 & SLK & 73 & GNRHR \\
\hline 37 & STK4 & 74 & AOC3 \\
\hline
\end{tabular}

PCBP3 increases the translation of PFKFB3. Overall, these results suggest that PCBP3 improves PFKFB3 expression levels by increasing its translation rather than by influencing its protein stability.
To determine the functional impact of PCBP3-mediated regulation of PFKFB3 expression in lung fibrosis, we transfected lung fibroblasts with FLAG-PCBP3. Expression of PFKFB3 was significantly increased by PCBP3 overexpression compared to that of the empty vector control. Reliable markers of the phenotypic transformation of fibroblasts into myofibroblasts, fibronectin, collagen I and a-SMA, were markedly increased in FLAG-PCBP3treated cells at the protein level (Figures 3G,H) compared with vector-treated cells. In turn, using small interfering RNA (siRNA) to silence PFKFB3, the FLAG-PCBP3-induced overexpression of fibronectin, collagen I and a-SMA was abolished (Figures 3G,H). These findings suggest that PCBP3 protein upregulation is an early and sustained event during fibroblast activation and that the profibrogenic effects of PCBP3 are mediated by PFKFB3 expression. Taken together, these data suggest that PCBP3 posttranscriptionally increases PFKFB3 expression by promoting its translation during myofibroblast activation.

\section{Anlotinib Represses PCBP3 Expression Levels During Myofibroblast Activation}

To confirm the regulation of $\mathrm{PCBP} 3$ by anlotinib in vitro, we evaluated the protein expression of PCBP3 in MLFs and IMR90 cells. We found that TGF- $\beta 1$ induced the expression of PCBP3 in MLFs and that anlotinib prevented PCBP3 expression by immunofluorescence analysis (Figure 4A). Western blot analysis of PCBP3 showed a similar result (Figures 4B,C) in MLFs, and these results were confirmed in the human IMR90 cell line (Figures 4D,E). Taken together, these data suggest that anlotinib can repress PCBP3 expression levels during myofibroblast activation in vitro.

\section{Anlotinib Attenuates Bleomycin-Induced Pulmonary Fibrosis}

To investigate the biological effects of anlotinib on pulmonary fibrosis in vivo, we established a bleomycin (BLM)-induced mouse model of pulmonary fibrosis. The mice were intraperitoneally injected with $1 \mathrm{mg} / \mathrm{kg}$ anlotinib daily after BLM administration (Figure 5A). From the first week after bleomycin instillation, the bleomycin-treated mice showed a 
TABLE 5 | Potential proteins may interact with PFKFB3 mRNA through the catRAPID algorithm.

\begin{tabular}{|c|c|c|c|c|c|c|c|c|}
\hline$\#$ & Protein D & RNA ID & Z score ${ }^{?}$ & $\begin{array}{c}\text { Discriminative } \\
\text { power } \\
(\%)^{?}\end{array}$ & $\begin{array}{c}\text { Interaction } \\
\text { strength } \\
(\%)^{?}\end{array}$ & Domain? & Motif $?$ & Ranking? \\
\hline 1 & ELAV1_MOUSE_247-308 & NC_000068.7:c11_1_5924-6036 & -0.13 & 50 & 98 & yes & yes & $\mathrm{HHH}$ \\
\hline 2 & ELAV1_MOUSE_247-308 & $\begin{array}{c}\text { NC_000068.7: } \\
\text { c11_1_26816-27008 }\end{array}$ & -0.08 & 67 & 99 & yes & yes & $\mathrm{HHH}$ \\
\hline 3 & ELAV1_MOUSE_247-308 & $\begin{array}{c}\text { NC_000068.7: } \\
\text { c11_1_15806-15983 }\end{array}$ & -0.23 & 40 & 90 & yes & yes & $\mathrm{HHH}$ \\
\hline 4 & PCBP3_MOUSE_301-351 & $\begin{array}{c}\text { NC_000068.7: } \\
\text { c11_1_41382-41564 }\end{array}$ & -0.69 & 14 & 13 & yes & yes & $\mathrm{HHH}$ \\
\hline 5 & ELAV1_MOUSE_247-308 & $\begin{array}{c}\text { NC_000068.7: } \\
\text { c11_1_77223-77340 }\end{array}$ & -0.47 & 22 & 74 & yes & yes & $\mathrm{HHH}$ \\
\hline 6 & ELAV1_MOUSE_247-308 & $\begin{array}{c}\text { NC_000068.7: } \\
\text { c11_1_10399-10532 }\end{array}$ & -0.50 & 20 & 64 & yes & yes & $\mathrm{HHH}$ \\
\hline 7 & ELAV1_MOUSE_109-176 & NC_000068.7:c11_1_5924-6036 & -0.14 & 50 & 98 & yes & yes & $\mathrm{HHH}$ \\
\hline 8 & ELAV1_MOUSE_109-176 & $\begin{array}{c}\text { NC_000068.7: } \\
\text { c11_1_45706-45815 }\end{array}$ & -0.39 & 26 & 85 & yes & yes & $\mathrm{HHH}$ \\
\hline 9 & ELAV1_MOUSE_109-176 & $\begin{array}{c}\text { NC_000068.7: } \\
\text { c11_1_26816-27008 }\end{array}$ & -0.04 & 63 & 99 & yes & yes & $\mathrm{HHH}$ \\
\hline 10 & ELAV1_MOUSE_109-176 & $\begin{array}{c}\text { NC_000068.7: } \\
\text { c11_1_15806-15983 }\end{array}$ & -0.24 & 40 & 90 & yes & yes & $\mathrm{HHH}$ \\
\hline 11 & ELAV1_MOUSE_109-172 & NC_000068.7:c11_1_5924-6036 & -0.15 & 47 & 97 & yes & yes & $\mathrm{HHH}$ \\
\hline 12 & ELAV1_MOUSE_109-172 & $\begin{array}{c}\text { NC_000068.7: } \\
\text { c11_1_45706-45815 }\end{array}$ & -0.40 & 26 & 85 & yes & yes & $\mathrm{HHH}$ \\
\hline 13 & ELAV1_MOUSE_109-172 & $\begin{array}{c}\text { NC_000068.7: } \\
\text { c11_1_15806-15983 }\end{array}$ & -0.26 & 37 & 87 & yes & yes & $\mathrm{HHH}$ \\
\hline 14 & PCBP3_MOUSE_301-351 & $\begin{array}{c}\text { NC_000068.7: } \\
\text { c11_1_77461-77636 }\end{array}$ & -0.71 & 14 & 9 & yes & yes & $\mathrm{HHH}$ \\
\hline 15 & PCBP3_MOUSE_301-351 & $\begin{array}{c}\text { NC_000068.7: } \\
\text { c11_1_66050-66214 }\end{array}$ & -0.66 & 14 & 17 & yes & yes & $\mathrm{HHH}$ \\
\hline
\end{tabular}

certain reduction in activity, accompanied by slight shortness of breath. 21 days after bleomycin administration, bleomycintreated mice showed obvious hyperventilation, accompanied by reduced activity and weight loss, but no similar symptoms were observed in the control group. A single dose of BLM $(5 \mathrm{mg} / \mathrm{kg}$ ) administered by intratracheal instillation successfully induced pulmonary fibrosis in C57BL/6 mice, as evidenced by a decline in pulmonary function, decreased tidal volume (TV, Figure 5B) and dynamic compliance (Cdyn, Figure 5C), and increased lung resistance (RI, Figure 5D). However, treatment with anlotinib significantly reversed bleomycin-induced pulmonary dysfunction. Moreover, we evaluated collagen deposition in the lung tissues by analyzing the hydroxyproline (HYP) content and found that anlotinib treatment reduced the amount of collagen in the lungs of bleomycin-treated mice (Figure 5E). Hematoxylin and eosin (H\&E) staining indicated that anlotinib-treated mice had decreased lung inflammation and reduced lung architectural damage (Figure 5F). Accordingly, Masson's trichrome staining showed decreased collagen deposition in anlotinib-treated mice compared with vehicletreated mice (Figure 5F). Furthermore, attenuated fibrosis was supported by decreased protein levels of fibronectin and a-SMA by immunohistochemical (IHC) staining (Figure 5G). We also found that anlotinib treatment reduced fibronectin, collagen I and $\alpha$-SMA expression by western blotting (Figures $\mathbf{5 H , I}$ ). Taken together, these data show that anlotinib attenuates bleomycininduced pulmonary fibrosis in vivo.

\section{Anlotinib Decreases PCBP3 Expression and Inhibits PFKFB3-Driven Glycolysis in Fibrotic Rodent Lungs}

We next examined whether the levels of PCBP3 were regulated by anlotinib in vivo. We evaluated the expression of PCBP3 in lung tissues and found that the protein levels of PCBP3 were markedly increased after bleomycin instillation, while anlotinib treatment decreased PCBP3 expression (Figures 6A,B). Accordingly, IHC staining showed decreased PCBP3 protein levels in anlotinibtreated mice compared with vehicle-treated mice (Figure 6C). In addition, to confirm the regulation of PFKFB3-driven glycolysis by anlotinib in vivo, we measured the levels of lactate and the expression of PFKFB3 in the lungs of mice. We found that there were significantly higher levels of lactate in the lungs of bleomycin-treated mice than in the lungs of control mice, and anlotinib decreased lactate levels (Figure 6D). Western blot and IHC staining studies revealed that bleomycin-induced PFKFB3 expression in the lungs of mice was prevented by anlotinib (Figures 6E-G). Overall, these results suggest that anlotinib decreases PCBP3 expression and inhibits PFKFB3driven glycolysis in fibrotic rodent lungs.

\section{Anlotinib Accelerates the Resolution of Bleomycin-Induced Lung Fibrosis}

We demonstrated that anlotinib treatment could attenuate bleomycin-induced pulmonary fibrosis. In that in vivo 
experiment, anlotinib was administered at approximately the same time as bleomycin instillation. We further examined whether anlotinib could postpone the progression of established fibrosis. Therefore, we performed another in vivo experiment in which anlotinib was intraperitoneally injected 7 days after bleomycin instillation (Figure 7A). As interventions beginning 7 days post bleomycin were classified as therapeutic (Izbicki et al., 2002; Moeller et al., 2008), we initially treated mice with anlotinib ( $1 \mathrm{mg} / \mathrm{kg} /$ day or $2 \mathrm{mg} / \mathrm{kg} /$ day) beginning on day 7 after bleomycin instillation. Pulmonary function tests showed that anlotinib treatment reversed the bleomycin-induced decline in pulmonary function, with increases in TV (Figure 7B) and Cdyn (Figure 7C) and a decrease in RI (Figure 7D). HYP measurements showed that the collagen content was significantly decreased in anlotinib-treated mice compared with vehicle-treated mice (Figure 7E). H\&E staining and Masson's trichrome staining of lungs collected at day 21 showed enhanced recovery from fibrosis upon anlotinib treatment (Figure 7F). Correspondingly, IHC staining showed that anlotinib treatment reduced fibronectin and a-SMA expression in the lungs (Figure 7G). Western blot analysis also showed that anlotinib decreased the protein levels of fibronectin, collagen I and $\alpha$-SMA in the lungs (Figures 7H,I). Collectively, these data clearly demonstrate that anlotinib accelerates fibrosis resolution in vivo even after the establishment of fibrosis.

\section{DISCUSSION}

Despite recent advances in our understanding of IPF pathology, there is still no curative treatment for this disease; indeed, the currently available antifibrotic treatment modalities slow but do not completely stop the progression of the disease (Spagnolo and Maher, 2017). In this study, we demonstrate that anlotinib strongly inhibits fibroblast-to-myofibroblast transdifferentiation and reduces extracellular matrix production in primary MLFs and in the human IMR90 cell line. Accordingly, preventative and therapeutic administration of anlotinib to bleomycin-administered mice resulted in accelerated resolution of fibrosis. No adverse, systemic side effects were observed. Here, we demonstrate a novel mechanism by which anlotinib exerts antifibrotic effects by downregulating $\mathrm{PCBP} 3$, reducing PFKFB3 translation and inhibiting glycolysis in myofibroblasts (Figure 8).

A previous study revealed that male and female C57BL/6 mice did not differ in terms of their lung fibrotic responses, including cellular infiltration, collagen deposition, and quantifiable morphological changes in the lung architecture, but that the bleomycin-induced decrease in static compliance was significantly greater in males than in females (Voltz et al., 2008). This adverse effect on lung function was found to be due to male sex hormones. So sex differences should be carefully considered when interpreting experimental models of pulmonary fibrosis in mice (Blaauboer et al., 2014). In our study, we used only female mice to avoid the sex differences. We found that anlotinib exerted the preventative effects on bleomycin model of pulmonary fibrosis. Furthermore, anlotinib can also accelerate fibrosis resolution after the establishment of fibrosis.
A recent report showed that anlotinib inhibits the profibrotic effect of TGF- $\beta 1$ in lung fibroblasts by attenuating inflammation and oxidative stress (Ruan et al., 2020). Our data are in line with that report and reveal an additional mechanism by which anlotinib acts on lung fibroblasts to attenuate fibrosis. There is emerging evidence about the association between metabolic disorders and IPF (Yin et al., 2019; Cho et al., 2020; Hu et al., 2020). Similar to highly proliferative cancer cells, myofibroblasts are highly dependent on glycolysis in vitro (Bueno et al., 2020). Furthermore, glycolysis is necessary not only for fibroblast growth and migration but also for the acquisition and maintenance of a myofibroblastic phenotype (Xu et al., 2017; Para et al., 2019). A previous study revealed that inhibition of glycolysis by the PFKFB3 inhibitor $3 \mathrm{PO}$ or by genomic disruption of the PFKFB3 gene blunted the differentiation of lung fibroblasts into myofibroblasts and attenuated profibrotic phenotypes in myofibroblasts (Xie et al., 2015). Another study revealed that lung fibroblasts displayed augmented aerobic glycolysis through activation of the PI3K-Akt-mTOR/PFKFB3 pathway in LPS-induced pulmonary fibrosis (Hu et al., 2020). Our data, along with previous studies, demonstrated that glycolytic reprogramming was critical to lung myofibroblast activation and pulmonary fibrosis. Furthermore, we demonstrated that anlotinib could strongly inhibit glycolytic reprogramming in vitro and in vivo.

The results presented herein provide new insights into the molecular mechanisms of lung fibrogenesis. This work unveils a previously unrecognized posttranscriptional regulation in activated lung fibroblasts composed of the RNA binding protein PCBP3 and the critical glycolytic enzyme PFKFB3, which maintains fibroblasts with higher glycolytic activity in fibrotic lungs compared to normal lung fibroblasts in healthy lungs. PCBP family members perform multiple functions by binding to the poly $(\mathrm{C})$ sequence in both DNA and RNA to modulate mRNA stabilization, translation silencing, or translation enhancement (Blyn et al., 1997; Andino et al., 1999; Ostareck et al., 2001). Our present findings showing that PCBP3 plays an important role in myofibroblast activation and fibrogenesis and significantly extends our previous understanding by identifying an additional node of interaction between PCBP3mediated posttranscriptional dysregulation and lung disease. We found that PFKFB3 protein overexpression was not accompanied by PFKFB3 mRNA upregulation, indicating that this increase was not transcriptionally derived. Instead, we observed that high PFKFB3 protein levels were maintained during fibroblast transdifferentiation, owing to $\mathrm{PCBP} 3$-mediated translational activation. Thus, the PCBP3 protein is upregulated during myofibroblast activation and binds directly to PFKFB3 during transcription. This binding activates PFKFB3 mRNA translation and generates high levels of the glycolysis activator PFKFB3. This mechanism does not exclude additional pathways of regulating PFKFB3 expression. Hence, it is not unusual for key proteins to be regulated at multiple levels, including through transcription, translation, and posttranslational modifications.

Our study is the first to report that anlotinib inhibits PFKFB3mediated glycolysis in myofibroblasts. Moreover, anlotinib 
attenuates glycolysis in myofibroblasts by repressing PCBP3 expression levels rather than directly regulating the expression of PFKFB3, as anlotinib treatment does not decrease the mRNA levels of PFKFB3. Our work contributes novel mechanistic insight into the action of anlotinib. However, one of the limitations of this study is that we didn't knock out PCBP3/PFKFB3 in mice to verify their effects in lung fibrosis, which may be explored in the further research. This future direction may be important to better understand how PCBP3 regulates PFKFB3-mediated glycolysis in pulmonary fibrosis. The other one is that this study only used bleomycin mice model for the research. Although the bleomycin model is the most widely used and best-characterized mouse model, the fibrosis of the bleomycin model is self-resolving, which contrasts with the progressive chronic fibrosis typical of human IPF (Liu et al., 2017). Therefore, whether anlotinib could attenuate fibrosis in human IPF still requires ex vivo models of pulmonary fibrosis.

In conclusion, our study demonstrated a clear antifibrotic role for anlotinib in the lungs. Its antifibrotic activity is mediated by its ability to decrease PCBP3 expression and attenuate PFKFB3driven glycolysis, thereby inhibiting myofibroblast activation. Anlotinib might be considered as a potential therapeutic option for IPF patients.

\section{DATA AVAILABILITY STATEMENT}

The original contributions presented in the study are included in the article/Supplementary Material, further inquiries can be directed to the corresponding authors.

\section{REFERENCES}

Agostini, F., Zanzoni, A., Klus, P., Marchese, D., Cirillo, D., and Tartaglia, G. G. (2013). catRAPID Omics: a Web Server for Large-Scale Prediction of ProteinRNA Interactions. Bioinformatics 29 (22), 2928-2930. doi:10.1093/ bioinformatics/btt495

Andino, R., Böddeker, N., Silvera, D., and Gamarnik, A. V. (1999). Intracellular Determinants of Picornavirus Replication. Trends Microbiol. 7 (2), 76-82. doi:10.1016/s0966-842x(98)01446-2

Atsumi, T., Chesney, J., Metz, C., Leng, L., Donnelly, S., Makita, Z., et al. (2002). High Expression of Inducible 6-Phosphofructo-2-Kinase/fructose-2,6Bisphosphatase (iPFK-2; PFKFB3) in Human Cancers. Cancer Res. 62 (20), 5881-5887. doi:10.2337/diabetes.54.12.3349

Blaauboer, M. E., Boeijen, F. R., Emson, C. L., Turner, S. M., Zandieh-Doulabi, B., Hanemaaijer, R., et al. (2014). Extracellular Matrix Proteins: a Positive Feedback Loop in Lung Fibrosis? Matrix Biol. 34, 170-178. doi:10.1016/ j.matbio.2013.11.002

Blyn, L. B., Towner, J. S., Semler, B. L., and Ehrenfeld, E. (1997). Requirement of poly(rC) Binding Protein 2 for Translation of Poliovirus RNA. J. Virol. 71 (8), 6243-6246. doi:10.1128/jvi.71.8.6243-6246.1997

Bueno, M., Calyeca, J., Rojas, M., and Mora, A. L. (2020). Mitochondria Dysfunction and Metabolic Reprogramming as Drivers of Idiopathic Pulmonary Fibrosis. Redox Biol. 33, 101509. doi:10.1016/j.redox.2020.101509

Cao, Y., Zhang, X., Wang, L., Yang, Q., Ma, Q., Xu, J., et al. (2019). PFKFB3mediated Endothelial Glycolysis Promotes Pulmonary Hypertension. Proc. Natl. Acad. Sci. U S A. 116 (27), 13394-13403. doi:10.1073/pnas.1821401116

Chen, Y., Xu, T., Li, M., Li, C., Ma, Y., Chen, G., et al. (2021). Inhibition of SENP2-Mediated Akt deSUMOylation Promotes Cardiac Regeneration via Activating Akt Pathway. Clin. Sci. (Lond) 135 (6), 811-828. doi:10.1042/ cs20201408

\section{ETHICS STATEMENT}

The animal study was reviewed and approved by Southern Medical University Institutional Animal Care and Use Committee.

\section{AUTHOR CONTRIBUTIONS}

WC, JZ, and WZ performed study concept and design; YL, YL, and $\mathrm{ZZ}$ performed development of methodology and writing; $\mathrm{HH}$ and $\mathrm{XW}$ provided acquisition, analysis and interpretation of data, and statistical analysis; XM and FZ provided technical and material support; SC and HD performed review and revision of the paper.

\section{FUNDING}

This work was supported by National Natural Science Foundation of China (No. 81870058, 81600648, 81970032, and 81870058), National Natural Science Foundation of Guangdong Province (NO. 2017A030313849).

\section{SUPPLEMENTARY MATERIAL}

The Supplementary Material for this article can be found online at: https://www.frontiersin.org/articles/10.3389/fphar.2021.744826/ full\#supplementary-material

Chen, Z., Liu, M., Li, L., and Chen, L. (2018). Involvement of the Warburg Effect in Non-tumor Diseases Processes. J. Cel Physiol. 233 (4), 2839-2849. doi:10.1002/ jcp. 25998

Cho, S. J., Moon, J. S., Nikahira, K., Yun, H. S., Harris, R., Hong, K. S., et al. (2020). GLUT1-dependent Glycolysis Regulates Exacerbation of Fibrosis via AIM2 Inflammasome Activation. Thorax 75 (3), 227-236. doi:10.1136/thoraxjnl2019-213571

Choi, H. S., Kim, C. S., Hwang, C. K., Song, K. Y., Law, P. Y., Wei, L. N., et al. (2007). Novel Function of the Poly(C)-binding Protein Alpha CP3 as a Transcriptional Repressor of the Mu Opioid Receptor Gene. FASEB J. 21 (14), 3963-3973. doi:10.1096/fj.07-8561com

De Bock, K., Georgiadou, M., Schoors, S., Kuchnio, A., Wong, B. W., Cantelmo, A. R., et al. (2013). Role of PFKFB3-Driven Glycolysis in Vessel Sprouting. Cell 154 (3), 651-663. doi:10.1016/j.cell.2013.06.037

DeBerardinis, R. J., and Thompson, C. B. (2012). Cellular Metabolism and Disease: what Do Metabolic Outliers Teach Us? Cell 148 (6), 1132-1144. doi:10.1016/ j.cell.2012.02.032

Gfeller, D., Grosdidier, A., Wirth, M., Daina, A., Michielin, O., and Zoete, V. (2014). SwissTargetPrediction: a Web Server for Target Prediction of Bioactive Small Molecules. Nucleic Acids Res. 42, W32-W38. doi:10.1093/nar/gku293

Hinz, B. (2012). Mechanical Aspects of Lung Fibrosis: a Spotlight on the Myofibroblast. Proc. Am. Thorac. Soc. 9 (3), 137-147. doi:10.1513/ pats.201202-017AW

Hinz, B., Phan, S. H., Thannickal, V. J., Prunotto, M., Desmoulière, A., Varga, J., et al. (2012). Recent Developments in Myofibroblast Biology: Paradigms for Connective Tissue Remodeling. Am. J. Pathol. 180 (4), 1340-1355. doi:10.1016/ j.ajpath.2012.02.004

Ho, R. C., Alcazar, O., Fujii, N., Hirshman, M. F., and Goodyear, L. J. (2004). p38gamma MAPK Regulation of Glucose Transporter Expression and Glucose Uptake in L6 Myotubes and Mouse Skeletal Muscle. Am. J. Physiol. Regul. Integr. Comp. Physiol. 286 (2), R342-R349. doi:10.1152/ajpregu.00563.2003 
Hu, X., Xu, Q., Wan, H., Hu, Y., Xing, S., Yang, H., et al. (2020). PI3K-Akt-mTOR/ PFKFB3 Pathway Mediated Lung Fibroblast Aerobic Glycolysis and Collagen Synthesis in Lipopolysaccharide-Induced Pulmonary Fibrosis. Lab. Invest. 100 (6), 801-811. doi:10.1038/s41374-020-0404-9

Huang, Y., Wang, Y., Wang, X., Lin, L., Wang, P., Sun, J., et al. (2020). The Effects of the Transforming Growth Factor-B1 (TGF-B1) Signaling Pathway on Cell Proliferation and Cell Migration Are Mediated by Ubiquitin Specific Protease 4 (USP4) in Hypertrophic Scar Tissue and Primary Fibroblast Cultures. Med. Sci. Monit. 26, e920736. doi:10.12659/msm.920736

Hutchinson, J., Fogarty, A., Hubbard, R., and McKeever, T. (2015). Global Incidence and Mortality of Idiopathic Pulmonary Fibrosis: a Systematic Review. Eur. Respir. J. 46 (3), 795-806. doi:10.1183/09031936.00185114

Izbicki, G., Segel, M. J., Christensen, T. G., Conner, M. W., and Breuer, R. (2002). Time Course of Bleomycin-Induced Lung Fibrosis. Int. J. Exp. Pathol. 83 (3), 111-119. doi:10.1046/j.1365-2613.2002.00220.x

Jarman, E. R., Khambata, V. S., Cope, C., Jones, P., Roger, J., Ye, L. Y., et al. (2014). An Inhibitor of NADPH Oxidase-4 Attenuates Established Pulmonary Fibrosis in a Rodent Disease Model. Am. J. Respir. Cel. Mol. Biol. 50 (1), 158-169. doi:10.1165/rcmb.2013-0174OC

Kang, D. H., Song, K. Y., Choi, H. S., Law, P. Y., Wei, L. N., and Loh, H. H. (2012). Novel Dual-Binding Function of a Poly (C)-binding Protein 3, Transcriptional Factor Which Binds the Double-Strand and Single-Stranded DNA Sequence. Gene 501 (1), 33-38. doi:10.1016/j.gene.2012.04.001

Kenyon, N. J., Ward, R. W., McGrew, G., and Last, J. A. (2003). TGF-betal Causes Airway Fibrosis and Increased Collagen I and III mRNA in Mice. Thorax 58 (9), 772-777. doi:10.1136/thorax.58.9.772

Kim, Y., Noren Hooten, N., Dluzen, D. F., Martindale, J. L., Gorospe, M., and Evans, M. K. (2015). Posttranscriptional Regulation of the Inflammatory Marker C-Reactive Protein by the RNA-Binding Protein HuR and MicroRNA 637. Mol. Cel. Biol. 35 (24), 4212-4221. doi:10.1128/ mcb.00645-15

Leidgens, S., Bullough, K. Z., Shi, H., Li, F., Shakoury-Elizeh, M., Yabe, T., et al. (2013). Each Member of the poly-R(C)-binding Protein 1 (PCBP) Family Exhibits Iron Chaperone Activity toward Ferritin. J. Biol. Chem. 288 (24), 17791-17802. doi:10.1074/jbc.M113.460253

Liang, L., Hui, K., Hu, C., Wen, Y., Yang, S., Zhu, P., et al. (2019). Autophagy Inhibition Potentiates the Anti-angiogenic Property of Multikinase Inhibitor Anlotinib through JAK2/STAT3/VEGFA Signaling in Non-small Cell Lung Cancer Cells. J. Exp. Clin. Cancer Res. 38 (1), 71. doi:10.1186/s13046-0191093-3

Liu, G., Philp, A. M., Corte, T., Travis, M. A., Schilter, H., Hansbro, N. G., et al. (2021). Therapeutic Targets in Lung Tissue Remodelling and Fibrosis. Pharmacol. Ther. 225, 107839. doi:10.1016/ j.pharmthera.2021.107839

Liu, T., De Los Santos, F. G., and Phan, S. H. (2017). The Bleomycin Model of Pulmonary Fibrosis. Methods Mol. Biol. 1627, 27-42. doi:10.1007/978-1-49397113-8_2

Livi, C. M., Klus, P., Delli Ponti, R., and Tartaglia, G. G. (2016). catRAPID Signature: Identification of Ribonucleoproteins and RNA-Binding Regions. Bioinformatics 32 (5), 773-775. doi:10.1093/bioinformatics/ btv629

Meng, Y., Yu, C. H., Li, W., Li, T., Luo, W., Huang, S., et al. (2014). Angiotensinconverting Enzyme 2/angiotensin-(1-7)/Mas axis Protects against Lung Fibrosis by Inhibiting the MAPK/NF-кB Pathway. Am. J. Respir. Cel. Mol. Biol. 50 (4), 723-736. doi:10.1165/rcmb.2012-0451OC

Moeller, A., Ask, K., Warburton, D., Gauldie, J., and Kolb, M. (2008). The Bleomycin Animal Model: a Useful Tool to Investigate Treatment Options for Idiopathic Pulmonary Fibrosis? Int. J. Biochem. Cel. Biol. 40 (3), 362-382. doi:10.1016/j.biocel.2007.08.011

Nigdelioglu, R., Hamanaka, R. B., Meliton, A. Y., O'Leary, E., Witt, L. J., Cho, T., et al. (2016). Transforming Growth Factor (TGF)- $\beta$ Promotes De Novo Serine Synthesis for Collagen Production. J. Biol. Chem. 291 (53), 27239-27251. doi:10.1074/jbc.M116.756247

Ostareck, D. H., Ostareck-Lederer, A., Shatsky, I. N., and Hentze, M. W. (2001). Lipoxygenase mRNA Silencing in Erythroid Differentiation: The 3'UTR Regulatory Complex Controls 60S Ribosomal Subunit Joining. Cell 104 (2), 281-290. doi:10.1016/s0092-8674(01)00212-4
Papa, S., Choy, P. M., and Bubici, C. (2019). The ERK and JNK Pathways in the Regulation of Metabolic Reprogramming. Oncogene 38 (13), 2223-2240. doi:10.1038/s41388-018-0582-8

Para, R., Romero, F., George, G., and Summer, R. (2019). Metabolic Reprogramming as a Driver of Fibroblast Activation in PulmonaryFibrosis. Am. J. Med. Sci. 357 (5), 394-398. doi:10.1016/j.amjms.2019.02.003

Plantier, L., Cazes, A., Dinh-Xuan, A. T., Bancal, C., Marchand-Adam, S., and Crestani, B. (2018). Physiology of the Lung in Idiopathic Pulmonary Fibrosis. Eur. Respir. Rev. 27 (147), 170062. doi:10.1183/ 16000617.0062-2017

Ruan, H., Lv, Z., Liu, S., Zhang, L., Huang, K., Gao, S., et al. (2020). Anlotinib Attenuated Bleomycin-Induced Pulmonary Fibrosis via the TGF-B1 Signalling Pathway. J. Pharm. Pharmacol. 72 (1), 44-55. doi:10.1111/jphp.13183

Safran, M., Solomon, I., Shmueli, O., Lapidot, M., Shen-Orr, S., Adato, A., et al. (2002). GeneCards 2002: towards a Complete, Object-Oriented, Human Gene Compendium. Bioinformatics 18 (11), 1542-1543. doi:10.1093/bioinformatics/ 18.11.1542

Sapudom, J., Rubner, S., Martin, S., Thoenes, S., Anderegg, U., and Pompe, T. (2015). The Interplay of Fibronectin Functionalization and TGF-B1 Presence on Fibroblast Proliferation, Differentiation and Migration in 3D Matrices. Biomater. Sci. 3 (9), 1291-1301. doi:10.1039/c5bm00140d

Sato, S., Shinohara, S., Hayashi, S., Morizumi, S., Abe, S., Okazaki, H., et al. (2017). Anti-fibrotic Efficacy of Nintedanib in Pulmonary Fibrosis via the Inhibition of Fibrocyte Activity. Respir. Res. 18 (1), 172. doi:10.1186/s12931-017-0654-2

Spagnolo, P., and Maher, T. M. (2017). Clinical Trial Research in Focus: Why Do So many Clinical Trials Fail in IPF? Lancet Respir. Med. 5 (5), 372-374. doi:10.1016/s2213-2600(17)30122-4

Sun, Y., Niu, W., Du, F., Du, C., Li, S., Wang, J., et al. (2016). Safety, Pharmacokinetics, and Antitumor Properties of Anlotinib, an Oral Multi-Target Tyrosine Kinase Inhibitor, in Patients with Advanced Refractory Solid Tumors. J. Hematol. Oncol. 9 (1), 105. doi:10.1186/ s13045-016-0332-8

Szklarczyk, D., Gable, A. L., Lyon, D., Junge, A., Wyder, S., Huerta-Cepas, J., et al. (2019). STRING V11: Protein-Protein Association Networks with Increased Coverage, Supporting Functional Discovery in Genome-wide Experimental Datasets. Nucleic Acids Res. 47, D607-D613. doi:10.1093/nar/gky1131

Taniguchi, H., Ebina, M., Kondoh, Y., Ogura, T., Azuma, A., Suga, M., et al. (2010). Pirfenidone in Idiopathic Pulmonary Fibrosis. Eur. Respir. J. 35 (4), 821-829. doi:10.1183/09031936.00005209

Taurin, S., Yang, C. H., Reyes, M., Cho, S., Coombs, D. M., Jarboe, E. A., et al. (2018). Endometrial Cancers Harboring Mutated Fibroblast Growth Factor Receptor 2 Protein Are Successfully Treated with a New Small Tyrosine Kinase Inhibitor in an Orthotopic Mouse Model. Int. J. Gynecol. Cancer 28 (1), 152-160. doi:10.1097/igc.0000000000001129

Van Schaftingen, E., Lederer, B., Bartrons, R., and Hers, H. G. (1982). A Kinetic Study of Pyrophosphate: Fructose-6-Phosphate Phosphotransferase from Potato Tubers. Application to a Microassay of Fructose 2, 6-bisphosphate. Eur. J. Biochem. 129 (1), 191-195. doi:10.1111/j.1432-1033.1982.tb07039.x

Voltz, J. W., Card, J. W., Carey, M. A., Degraff, L. M., Ferguson, C. D., Flake, G. P., et al. (2008). Male Sex Hormones Exacerbate Lung Function Impairment after Bleomycin-Induced Pulmonary Fibrosis. Am. J. Respir. Cel. Mol. Biol. 39 (1), 45-52. doi:10.1165/rcmb.2007-0340OC

Wang, F., Qi, X. M., Wertz, R., Mortensen, M., Hagen, C., Evans, J., et al. (2020a). p38 $\gamma$ MAPK Is Essential for Aerobic Glycolysis and Pancreatic Tumorigenesis. Cancer Res. 80 (16), 3251-3264. doi:10.1158/0008-5472.CAN-19-3281

Wang, J., Guo, X., Wang, D., and Yang, S. (2020b). Expression Patterns of Pcbp Gene Family Members during Zebrafish Embryogenesis. Gene Expr. Patterns 35, 119097. doi:10.1016/j.gep.2020.119097

Wynn, T. A., and Ramalingam, T. R. (2012). Mechanisms of Fibrosis: Therapeutic Translation for Fibrotic Disease. Nat. Med. 18 (7), 1028-1040. doi:10.1038/nm.2807

Xie, C., Wan, X., Quan, H., Zheng, M., Fu, L., Li, Y., et al. (2018). Preclinical Characterization of Anlotinib, a Highly Potent and Selective Vascular Endothelial Growth Factor Receptor-2 Inhibitor. Cancer Sci. 109 (4), 1207-1219. doi:10.1111/cas.13536

Xie, N., Tan, Z., Banerjee, S., Cui, H., Ge, J., Liu, R. M., et al. (2015). Glycolytic Reprogramming in Myofibroblast Differentiation and Lung Fibrosis. Am. 
J. Respir. Crit. Care Med. 192 (12), 1462-1474. doi:10.1164/rccm.2015040780OC

Xu, J., Li, J., Yu, Z., Rao, H., Wang, S., and Lan, H. (2017). HMGB1 Promotes HLF-1 Proliferation and ECM Production through Activating HIF1- $\alpha$-Regulated Aerobic Glycolysis. Pulm. Pharmacol. Ther. 45, 136-141. doi:10.1016/j.pupt.2017.05.015

Yin, X., Choudhury, M., Kang, J. H., Schaefbauer, K. J., Jung, M. Y., Andrianifahanana, M., et al. (2019). Hexokinase 2 Couples Glycolysis with the Profibrotic Actions of TGF- $\beta$. Sci. Signal. 12 (612), eaax4067. doi:10.1126/ scisignal.aax 4067

Conflict of Interest: The authors declare that the research was conducted in the absence of any commercial or financial relationships that could be construed as a potential conflict of interest.
Publisher's Note: All claims expressed in this article are solely those of the authors and do not necessarily represent those of their affiliated organizations, or those of the publisher, the editors and the reviewers. Any product that may be evaluated in this article, or claim that may be made by its manufacturer, is not guaranteed or endorsed by the publisher.

Copyright $\odot 2021$ Chen, Zhang, Zhong, Liu, Lu, Zeng, Huang, Wan, Meng, Zou, Cai and Dong. This is an open-access article distributed under the terms of the Creative Commons Attribution License (CC BY). The use, distribution or reproduction in other forums is permitted, provided the original author(s) and the copyright owner(s) are credited and that the original publication in this journal is cited, in accordance with accepted academic practice. No use, distribution or reproduction is permitted which does not comply with these terms. 